\title{
Neuraminidase inhibitors rewire neutrophil function in vivo in murine sepsis and ex vivo in COVID-19
}

Rodrigo O. Formiga ${ }^{1,2,10}$, Flávia C. Amaral ${ }^{1,2}$, Camila F. Souza ${ }^{2}$, Daniel A. G. B. Mendes $^{1,2}$, Carlos W. S. Wanderley ${ }^{3}$, Cristina B. Lorenzini ${ }^{1,2}$, Adara A. Santos ${ }^{1,4}$, Juliana Antônia ${ }^{1}$, Lucas F. Faria ${ }^{1}$, Caio C. Natale ${ }^{1,2}$, Nicholas M. Paula ${ }^{1,2}$, Priscila C. S. Silva ${ }^{1}$, Fernanda R. Fonseca ${ }^{5}$, Luan Aires ${ }^{1,2}$, Nicoli Heck ${ }^{1}$, Márick R. Starick ${ }^{1,2}$, Shana P. C. Barroso $^{6}$, Alexandre Morrot ${ }^{7}$, Johan Van Weyenbergh ${ }^{8}$, Regina Sordi $^{2}$, Frederico AlissonSilva ${ }^{9}$, Daniel S. Mansur ${ }^{1,4}$, Fernando Q. Cunha ${ }^{3}$, Edroaldo L. Rocha ${ }^{1,4}$, Véronique WitkoSarsat ${ }^{10}$, Pierre-Régis Burgel ${ }^{10,11}$, Clémance Martin ${ }^{10,11}$, Rosemeri Maurici ${ }^{5}$, André Báfica $^{1,4}$, Matthew S. Macauley ${ }^{12,13}$, Fernando Spiller ${ }^{1,2 *}$

${ }^{1}$ Laboratory of Immunobiology, ${ }^{2}$ Department of Pharmacology, ${ }^{4}$ Department of Microbiology, Immunology and Parasitology, ${ }^{5}$ Department of Clinical Medicine, Federal University of Santa Catarina (UFSC), Florianopolis, Santa Catarina, Brazil.

${ }^{3}$ Department of Pharmacology, School of Medicine of Ribeirao Preto, University of Sao Paulo, Ribeirao Preto, Sao Paulo, Brazil.

${ }^{6}$ Molecular Biology Laboratory, Institute of Biomedical Research, Marcilio Dias Naval Hospital, Navy of Brazil, Rio de Janeiro, Brazil.

${ }^{7}$ Tuberculosis Research Laboratory, Faculty of Medicine, Federal University of Rio de Janeiro, Rio de Janeiro, Brazil; Immunoparasitology Laboratory, Oswaldo Cruz Foundation, FIOCRUZ, Rio de Janeiro, Brazil. 
${ }^{8}$ Department of Microbiology, Immunology and Transplantation, Rega Institute for Medical Research, Laboratory for Clinical and Epidemiological Virology, KU Leuven, Leuven, Belgium.

${ }^{9}$ Department of Immunology, Paulo de Goes Institute of Microbiology, Federal University of Rio de Janeiro (UFRJ), Rio de Janeiro, Brazil.

${ }^{10}$ Université de Paris, Institut Cochin, INSERM U1016, CNRS, Paris, France,

${ }^{11}$ Department of Pneumology, AP-HP, Hôpital Cochin, F-75014 PARIS-France.

${ }^{12}$ Department of Chemistry, ${ }^{13}$ Department of Medical Microbiology and Immunology, University of Alberta, Edmonton, Alberta, Canada.

${ }^{*}$ Corresponding author: Fernando Spiller, Department of Pharmacology (FMC/CCB/UFSC), Av. Prof. Henrique da Silva Fontes, 321 - Trindade, Florianópolis SC, 88040-900, Tel.: +55-48-3721-4852. e-mail: fernando.spiller@ufsc.br, spiller.farmaco@gmail.com.

\section{Authors' contributions}

All named authors meet the general criteria for authorship of this manuscript, take responsibility for the work's integrity as a whole, and have given final approval for publication.

ROF, FCA, DM, RS, DSM, JVW, ELR, VWS, AB, MSM and FS designed experiments and analyzed data; ROF, FAC, CFS, DM, CWW, CLB, AAS, JA, LFF, CCN, NMP, PCS, FRF, FAS, LA, NH, AB and FS performed experiments; SB, AM, JVW, VWS, PRB, CM, ELR, MSM, FQC and RM contributed with critical reagents/tools/clinical samples; ROF, FS, AB wrote the manuscript. 


\section{Funding}

This work was funded by FAPESP-SCRIPPS (FS; 15/50387-4), Howard Hughes Medical Institute - Early Career Scientist (AB; 55007412), National Institutes of Health Global Research Initiative Program (AB; TW008276), FWO (grant G0D6817N), CAPES Computational Biology (DSM; 23038.010048/2013-27), CNPQ/COVID-19 (AB; 401209/2020-2), CNPQ/PQ Scholars (AB and DSM), CAPES/PrINT (FS, AB, DSM; 88881.311316/2018-01), Le programme de bourses d'excellence Eiffel (RF) and FAPESC Scholarship (DM).

Running Title: Sialidase inhibitors rewire neutrophil function

\section{Competing Interests statement}

The authors declare that no conflict of interest exists.

Word Count: 3,500 (excluding abstract, references and figure legends)

This article has methods and data supplement at the end of the main text.

\section{At a Glance}

In a severe systemic inflammatory response, such as sepsis and COVID-19, neutrophils play a central role in organ damage. Thus, finding new ways to inhibit the exacerbated response of these cells is greatly needed. Here, we demonstrate that in vitro treatment of whole blood with the viral neuraminidase inhibitors Oseltamivir or Zanamivir, inhibits the activity of human neuraminidases as well as the exacerbated response of neutrophils. In experimental models of severe sepsis, oseltamivir decreased neutrophil activation and increased the survival rate of mice. Moreover, Oseltamivir or Zanamivir ex vivo treatment of whole blood cells from severe COVID-19 patients rewire neutrophil function. 


\section{ABSTRACT}

Neutrophil overstimulation plays a crucial role in tissue damage during severe infections. Neuraminidase (NEU)-mediated cleavage of surface sialic acid has been demonstrated to regulate leukocyte responses. Here, we report that antiviral NEU inhibitors constrain host NEU activity, surface sialic acid release, ROS production, and NETs released by microbial-activated human neutrophils. In vivo, treatment with Oseltamivir results in infection control and host survival in peritonitis and pneumonia models of sepsis. Singlecell RNA sequencing re-analysis of publicly data sets of respiratory tract samples from critical COVID-19 patients revealed an overexpression of NEU1 in infiltrated neutrophils. Moreover, Oseltamivir or Zanamivir treatment of whole blood cells from severe COVID19 patients reduces host NEU-mediated shedding of cell surface sialic acid and neutrophil overactivation. These findings suggest that neuraminidase inhibitors can serve as hostdirected interventions to dampen neutrophil dysfunction in severe infections.

Abstract word count: 137 words.

Keywords: neuraminidase; sialic acid; sepsis; Oseltamivir; Zanamivir, neutrophil; SARS-CoV-2; COVID-19. 


\section{INTRODUCTION}

Neutrophils are key components of the immune response against pathogens (1). However, during severe acute infections, such as sepsis and COVID-19, overactivated neutrophils infiltrate vital organs and release molecules including proteases, reactive oxygen species (ROS), and neutrophil extracellular traps (NETs) $(2,3)$. While such inflammatory mediators are essential to the control of infection, they can also damage healthy cells (4). Therefore, the function of neutrophils must be regulated to efficiently clear microorganisms with minimal detrimental effects to the host.

A number of mechanisms controlling neutrophil activation have been described (5). For instance, the contents of sialic acid (Sia) have been demonstrated to regulate leukocyte activation to microbial stimuli (6). The dense array of Sia present in the glycocalyx of all mammalian cells makes this monosaccharide a central molecule for many cellular processes including: cell-cell interactions, signal transduction, and transendothelial migration (7). Neuraminidases (NEUs) are enzymes found in both pathogens and mammalian hosts, which hydrolyze Sia residues linked to galactose, Nacetylgalactosamine or polySia residues on glycoconjugates, thereby regulating many physiological and pathological responses (8). In human neutrophils, shedding of surface Sia by microbial-derived NEUs leads to cellular activation, ROS production, and release of NETs (9-12). Additionally, it has been demonstrated that LPS induces membraneassociated NEU activation in murine or human macrophages and dendritic cells (13). Upon LPS binding to TLR4, NEU activity was shown to regulate NF-KB induction in macrophages, suggesting a role for this enzyme during cellular activation (13). Also, in Gram-negative experimental sepsis, leukocyte dysfunction is mediated by NEU activity 
and associated with exacerbated inflammatory response and high mortality rates $(14,15)$. As previous studies have demonstrated that pathogen-derived NEU stimulate neutrophils, $(9,10,16)$, we investigated whether endogenous host NEUs can be targeted to regulate neutrophil dysfunction observed in severe infections.

Here, we have identified host NEU activation as a positive regulator of microbial-induced human neutrophil overactivation. Additionally, we have employed antiviral NEU inhibitors, Oseltamivir and Zanamivir, to explore this pathway and found that these drugs fine-tune the neutrophil dysfunction observed in sepsis and COVID-19. Together, our results show that NEU is a potential target for the control of neutrophil dysfunction and present Oseltamivir or Zanamivir as adjunctive therapy for severe infections.

\section{METHODS}

\section{Human blood samples}

Blood samples were collected from severe COVID-19 $(n=6)$ or convalescent COVID-19 $(n=8)$ patients (25 to $89 \mathrm{yr}$ old) admitted in the ICU or Research Center on Asthma and Airway Inflammation at the UFSC University Hospital. Blood samples from sex-matched healthy donors were used as controls. The research protocol was approved by the Institutional Review Board of the UFSC (CAAE \#82815718.2.0000.0121, $\# 36944620.5 .1001 .0121)$.

\section{Evaluation of neutrophil response}


Whole blood were incubated in the presence or absence of Oseltamivir (100 $\mu \mathrm{M}$, SigmaAldrich), Zanamivir (30 $\mu \mathrm{M}$, Sigma-Aldrich), LPS (1 $\mu \mathrm{g} / \mathrm{mL}$, E. coli 0127:b8, SigmaAldrich), LPS plus Oseltamivir or LPS plus Zanamivir. Total leukocytes were used to evaluate the effect of isolated neuraminidase from Clostridium perfringens (CpNEU) on neutrophils. Leukocytes were incubated in the presence or absence of CpNEU (10 mU, Sigma-Aldrich), CpNEU plus Oseltamivir or CpNEU plus Zanamivir. Next, neutrophil activation, phagocytosis, bacterial killing, ROS production and NETs release were evaluated.

\section{Mice}

All animal procedures followed the ARRIVE guidelines and the international principles for laboratory animal studies (17). Protocols were approved by the Animal Use Ethics Committee of UFSC (CEUA \#8278290818). C57BL/6 and Swiss mice were used for peritonitis- or pneumonia-induced severe sepsis. Mice were randomly pretreated and/or post treated by per oral (PO, 12/12 hr) with saline or Oseltamivir phosphate $(10 \mathrm{mg} / \mathrm{kg}$, Eurofarma, Brazil).

Additional details and methods are found in Supplementary Methods.

\section{RESULTS}

LPS-induced surface Sia shedding in human neutrophils is mediated by NEU activity 
As activated NEUs hydrolyze Sia residues linked to underlying galactose glycoconjugates (7), we estimate Sia levels on neutrophils after their activation. LPS treatment of whole blood from healthy donors significantly reduces the binding of Maackia amurensis II (MAL-II, a lectin that binds selectively to $\alpha 2-3$ - over $\alpha 2-6$-linked Sia (18)) on neutrophils when compared to untreated cells (Supplementary Fig. 2A). Next, cells were stained with an Fc-chimera of Siglec-9, a sialic acid-binding protein that recognizes Sia in $\alpha 2-3$ and $\alpha 2-6$ linkages (19). Similarly, binding of Siglec-9-Fc (Supplementary Fig. 2B) is decreased on neutrophils treated with LPS, confirming a reduction of neutrophil Sia residues likely due to LPS-induced NEU activity in these cells. To test this hypothesis, we measured NEU activity in human leukocytes using the NEU substrate 4-MU-NANA (13) and validated the assay using CpNEU (Fig. 1A-B). Both clinically available NEU inhibitors Oseltamivir and Zanamivir reduce CpNEU activity (Fig. 1A-B). LPS-induced NEU activity on leukocytes was also significantly inhibited by Oseltamivir or Zanamivir (Fig. 1C-D). Moreover, these NEU inhibitors prevent LPS- or CpNEU-mediated reduction of MAL-II (Fig. 1E-F; K-L) or Sambucus nigra (SNA) binding (SNA, a lectin that binds selectively to a2-6- over $\alpha 2-3-$ linked Sia) (Fig. 1G-H; M-N). Desialylation unmasks galactose residues that are recognized by the lectin peanut agglutinin (PNA) (20). NEU inhibitors prevent LPS- or CpNEU-mediated the increase of the PNA binding on neutrophils surface (Fig. 1I-J; O-P). Together, these results show that LPS-induced host NEU activity decreases Sia content on neutrophils, which can be inhibited by Oseltamivir and Zanamivir.

\section{LPS-induced phagocytosis and killing of $E$. coli is modulated by NEU activity}


Bacteria uptake and killing are important functions of neutrophils (3). We next investigated whether host NEU regulates phagocytosis and killing of $E$. coli. Whole blood or total leukocytes from healthy donors were preincubated with LPS or CpNEU, respectively, and E. coli BioParticles $®$ added to cells for $60 \mathrm{~min}$. Ingested pHrodo $E$. coli by neutrophils were analyzed by flow cytometry. A significant increase in the MFI of unstimulated cells incubated with pHrodo $E$. coli was observed at $37{ }^{\circ} \mathrm{C}$ compared to cells at $4{ }^{\circ} \mathrm{C}$ (Supplementary Fig. 3). LPS (Fig. 2A-C) or CpNEU, used as a positive control of NEU effects (Fig. 2D-F), but not heat-inactivated CpNEU, significantly enhances phagocytosis of E. coli. Remarkably, these effects are inhibited by Zanamivir or Oseltamivir (Fig. 2AF), suggesting that LPS-enhanced phagocytosis involves a host NEU-dependent pathway. Similarly, pretreatment of cells with LPS or CpNEU increases both the number of cells with bacteria as well as the number of bacteria per cell (Fig. 2G-J). These effects were also abolished when NEU inhibitors Oseltamivir and Zanamivir were added in the cell cultures (Fig. 2G-J). Furthermore, LPS or CpNEU treatment enhances intracellular and extracellular killing of E. coli, which are also inhibited by Oseltamivir or Zanamivir (Fig. 2K-L). These results suggest that NEU plays a critical role in LPS-upregulated phagocytosis and killing responses of neutrophils.

\section{NEU blockade prevents neutrophil activation}

Shedding of cell surface Sia by mobilization of granule-associated NEU to the cell surface has been associated with neutrophil activation (21). Therefore, we analyzed surface expression of CD66b and CD62L, two markers of human neutrophil activation (22-24) and $\alpha 2-3-S i a$ levels in LPS-exposed whole blood cultures. Both Oseltamivir and Zanamivir inhibit LPS-induced shedding of $\alpha 2-3-S i a$ (Fig. 3A,B) and CD62L (Fig. 3D,E) 
or upregulation of CD66b (Fig. 3G,H) on neutrophils. Similarly, MAL-Il preincubation, which prevents hydrolysis of $\alpha 2-3-S i a$ by NEU due to steric hindrance at the enzyme cleavage site (25), blocks LPS-induced neutrophil activation (Fig. 3C,F,I). These data show that dampening NEU activity or blocking the hydrolysis of $\alpha 2-3-S i a$ is sufficient to inhibit human neutrophil activation by LPS. Similar results were observed in soluble CpNEU-treated leukocytes (Supplementary Fig. 4). Next, we assessed whether NEU inhibitors influenced LPS-stimulated ROS production and release of NETs, key mediators of bacterial killing and tissue injury (26). Neutrophils primed with LPS and stimulated with PMA produce higher amounts of ROS when compared to unprimed cells (Fig. $\mathbf{3} \mathbf{J}-\mathbf{L}$ ). Both Oseltamivir and Zanamivir inhibit ROS release to levels similar to unprimed cells. These results were also reproduced by the treatment of cells with CpNEU (Supplementary Fig. 5E-G). Furthermore, Oseltamivir or Zanamivir significantly inhibit LPS-induced NETs released by isolated neutrophils (Fig. 3M). Together, these data indicate that microbialinduced host NEU activity regulates important neutrophil functions in vitro.

\section{Oseltamivir enhances survival rate of mice in clinically relevant models of sepsis}

Exacerbated neutrophil responses such as increased ROS production, release of NET and degranulation are associated with tissue injury and organ dysfunction (27). By using Oseltamivir as a therapeutic tool, we next explored the involvement of NEU activity in vivo during experimental sepsis, a model of neutrophil dysfunction $(3,28,29)$. We first induced sepsis by intraperitoneal administration of $1 \times 10^{7} \mathrm{CFU} / \mathrm{mice}$ of the Gram-negative E. coli (ATCC 25922), which lacks NEU in its genome (30). We used a dose of $10 \mathrm{mg} / \mathrm{Kg}$ of Oseltamivir by oral gavage, which is the equivalent dose used in humans $(\sim 7.5 \mathrm{mg} / \mathrm{Kg})$ (31). Oseltamivir pretreatment (2 hr before infection) plus post-treatment (6 hr after 
infection, 12/12 h, PO, for 4 days) markedly boost host survival (Supplementary Fig. 6A). Only a single dose of Oseltamivir $2 \mathrm{hr}$ before bacterial administration significantly decreases the number of neutrophils in the BAL and lung tissue 4 or $6 \mathrm{hr}$ after infection (Supplementary Fig. 6B-C). This pretreatment also augments neutrophil migration to the focus of infection, which is associated with an efficient control of infection (Supplementary Fig. 6D-F). Furthermore, pretreatment with Oseltamivir decreases BAL and plasma TNF and IL-17 levels (Supplementary Fig. 6G-J) and tissue injury markers (AST, ALT, ALP and total bilirubin) (Supplementary Fig. 6K-N), as well as prevents reduction of $\alpha 2-3-S i a$ on peritoneal lavage SSC ${ }^{\text {high }} /$ GR-1 ${ }^{\text {high }}$ cells (Supplementary Fig. 60P). More importantly, the post-treatment efficacy of Oseltamivir was also evaluated in survival of septic mice. Mice were IP challenged with $E$. coli $\left(1 \times 10^{7} \mathrm{CFU} / \mathrm{mice}\right)$ and treated $6 \mathrm{hr}$ after infection with Oseltamivir for 4 days (10 mg/Kg, PO, 12/12h). Strikingly, in the post-treatment protocol, Oseltamivir provides a significant improvement in the survival rate of septic mice (Supplementary Fig. 6Q).

Next, we employed the CLP model to evaluate the effect of Oseltamivir in septic mice, as it is considered the gold standard in preclinical sepsis (32). Six hours after CLP, Oseltamivir post-treatment leads to a small delay in the mortality rate of severe septic mice (Supplementary Fig. 7A). Next, CLP septic mice were treated with antibiotics because it is one of the standard interventions used in clinical settings of sepsis (33). Importantly, compared to the control animals, therapeutic use of Oseltamivir plus antibiotics drastically improved survival rates of CLP mice $(87.5 \%$ experimental group vs 25\% control group) (Supplementary Fig. 7B). Forty-eight hr after surgery, post-treated septic mice have a significant reduction of neutrophils in BAL and lungs, improvement of 
neutrophil migration at the focus of infection, and reduced bacterial load in PL and blood (Supplementary Fig. 7C- G). Levels of TNF and IL-17 in PL and plasma and tissue injury markers were also reduced in Oseltamivir treated mice (Supplementary Fig. 7H-O). Additionally, Oseltamivir also leads to a higher expression of $\alpha 2-3-S i a$ on SSC ${ }^{\text {igh }} / G R-1^{\text {igh }}$ cells in PL (Supplementary Fig. 7P-Q) confirming blockade of NEU activity in vivo.

As respiratory tract infections, particularly pneumonia, are among the most common sites of infection in sepsis (34), we intratracheally administered K. pneumoniae (ATCC 700603) into mice to address the effect of Oseltamivir. Post-treatment of mice with Oseltamivir significantly improves survival of septic mice challenged with $K$. pneumoniae (FIG. 4A). The increased host survival was accompanied by a decrease of neutrophil migration in BAL, reduced levels of TNF and IL-17 and reduced levels of tissue injury markers (Fig. 4B-K). Oseltamivir also prevents reduction of $\alpha 2-3-S i a$ on BAL SSC ${ }^{\text {igh }} / \mathrm{GR}^{-1^{\text {nigh }}}$ cells (Fig. 4L-M). Together, these results show that host NEU activation exacerbates inflammatory responses during sepsis and the use of Oseltamivir improves disease outcome.

\section{Oseltamivir and Zanamivir rescue overactivated neutrophils from COVID-19 patients}

Similar to bacterial sepsis, recent evidence suggests that neutrophils fuel hyperinflammatory response during severe SARS-CoV-2 infection. Larger numbers of circulating neutrophils have been associated with poor prognosis of COVID-19 patients and analysis of lung biopsies and autopsy specimens showed extensive neutrophil infiltration (2, 35-41). Further studies by Chua et al. (2020) employing single-cell RNA sequencing (scRNA-seq) from upper and lower respiratory tract samples from COVID-19 
patients indicated a significant augmentation of neutrophils linked to transcriptional program associated with tissue damage in epithelial and immune cells (42). Re-analysis of this scRNA-seq data (42) shows that expression of NEU1, but not NEU3 or NEU4, is upregulated in resident cells and highly expressed in neutrophils found in nasopharyngeal/pharyngeal swabs from COVID-19 patients (Fig. 5). A similar profile of NEUs expression was also observed in lower respiratory tract samples from these patients (Supplementary Fig. 8). These results suggest NEU enzymes are highly (41) expressed by lung infiltrating neutrophils during severe COVID-19. As demonstrated by Schulte-Schrepping et al. (2020) (43), circulating neutrophils are highly activated on active, but not convalescent, COVID-19 patients as observed by CD62L shedding (Fig. 6A) and upregulation of CD66b (Fig. 6B). Moreover, neutrophils from severe COVID-19 patients were found to present a significant reduction of surface $\alpha 2-3-$ Sia (Fig. 6C,D), suggesting that NEU activity is also increased in blood neutrophils during severe COVID19. Therefore, we asked whether neuraminidase inhibitors can rescue neutrophil activation from COVID-19 patients. Ex vivo treatment of whole blood with Oseltamivir or Zanamivir decreased neutrophil activation and restored the levels of cell surface sialic acid (Fig. 6E-I). As soluble NEU enzymes are also present in plasma (14), we next asked if plasma from COVID-19 patients can induce neutrophil response from healthy donors. Indeed, stimulation of whole blood from healthy donors with fresh plasma from severe, but not convalescent, COVID-19 patients leads to neutrophil activation (Fig. 6J), reduction of $\alpha 2-3-S i a$ (Fig. 6K) as well as ROS production (Fig. 6L,M), which were significantly reduced by Oseltamivir or Zanamivir (Fig. 6J-M). Additionally, activity of NEU is increased in plasma from severe COVID-19 patients (Supplementary Fig. 9A). Plasma samples from severe COVID-19 patients that were heat-inactivated to inhibit 
soluble NEU activity (Supplementary Fig. 9B) still induces neutrophil activation (Fig. 6JM), suggesting that cellular NEU in conjunction with circulating factors mediate NEUdependent neutrophil activation in severe COVID-19. These results highlight host NEU as a regulator of neutrophil activation in severe COVID-19 and suggest this pathway as a potential host-directed intervention target to rewire neutrophil responses during severe diseased.

\section{DISCUSSION}

Systemic inflammatory responses may lead to unsuitable neutrophil stimulation, which is associated with higher mortality rates in sepsis and sepsis-like diseases (44). Therefore, finding new therapeutic options to prevent neutrophil overstimulation while maintaining their microbicidal abilities is greatly needed. Based on the findings presented here, NEU inhibitors are promising drugs to fill this gap. We demonstrated that endogenous host NEUs mediate exacerbated inflammatory responses by primary neutrophils. Clinically used viral NEU inhibitors, Oseltamivir and Zanamivir, decrease human NEU activity and are effective in preventing LPS-induced neutrophil responses or to rescue overactivation of neutrophils from COVID-19 patients. In severe murine sepsis, therapeutic use of Oseltamivir fine-tunes neutrophil migration promoting bacterial clearance and high survival rates.

All of the four different isotypes of NEU described in mammals (NEU1, NEU2, NEU3 and NEU4) remove Sia from glycoproteins and glycolipids with specific substrate preferences 
(45). NEU1 cleaves preferentially $\alpha 2-3-S i a$ and seems to be the most important isoenzyme in immune cells. NEU1 is a lysosomal enzyme but it is also present at the cell surface where it can regulate multiple receptors such as Fc gamma receptor (FcyR), insulin receptor, integrin $\beta-4$, and TLRs (46). While several stimuli were described to induce NEU activity including LPS (13), PMA, calcium ionophore A23187, fMLP (21), and IL-8 (47), how NEUs are activated is poorly understood. However, NEU1 activation involves formation of a multicomplex of enzymes that stabilizes NEU1 in its conformational active state (48). Interestingly, NEU1 was found to be associated with matrix metalloproteinase-9 (MMP9) at the surface of naive macrophages (49). LPS binding to TLR4 leads to activation of a G protein-coupled receptor (GPCR) via Gai subunit and MMP9 to induce NEU1 activity, which in turn removes $\alpha 2-3-S i a$ from TLR4, allowing its dimerization and intracellular signaling $(25,49,50)$. Although we have not formally addressed whether the LPS-TLR4 pathway directly activates NEU function in human neutrophils, our results employing MAL-II preincubation suggest desialylation is required for LPS-mediated neutrophil responses. Thus, it is possible that NEU controls Sia levels in TLR4 molecules in human neutrophils as observed in macrophages and dendritic cells $(25,50)$.

The upstream involvement of NEU regulating LPS responses by neutrophils is in agreement with the previous demonstration that TLRs stimulate these cells independent of gene transcription (51). Together, our data suggests that NEU activation provides a fast response to enhance microbial-induced neutrophil functions. Thus, we speculate that this could be an evolutionary mechanism by which neutrophils quickly mobilize their microbicidal mediators against pathogens. 
Sialic acid removal from the surface of neutrophils markedly changes their adhesiveness, chemotaxis, and migration $(21,47,56-58)$. In peritonitis- or pneumonia-induced sepsis in mice, we observed that Oseltamivir prevented the massive neutrophil infiltration into bronchoalveolar spaces or lung tissues, suggesting that regulation of neutrophil migration by dampening NEU activity contributes to survival of septic mice. Interestingly, we observed a divergent effect of Oseltamivir on neutrophil migration to the focus of infection between peritonitis- and pneumonia-induced sepsis. This could be explained by the different mechanisms involved in neutrophil migration to the peritoneal cavity and lungs. While expression of CD62L and rolling of neutrophils to endothelium is necessary for its migration to the peritoneal cavity, it seems to be not required for migration into the lungs $(3,59)$. Moreover, systemic neutrophil activation leads to cell stiffening, resulting in retention of neutrophils in the small capillaries of the lungs (60), which is frequently the first organ impaired in non-pneumonia- and pneumonia-induced sepsis (61).

The role of NEU-induced neutrophil activation suggested here agrees with previous demonstration that NEU1 deletion in hematopoietic cells confers resistance to endotoxemia (15). Also, the sialidase inhibitor Neu5Gc2en protects endotoxemic irradiated wild-type (WT) mice reconstituted with WT bone marrow but not WT mice reconstituted with NEU1 bone marrow cells (15). Similar to our findings, the treatment of mice with NEU inhibitors increases host survival in E. coli-induced sepsis (14). This outcome was correlated with significant inhibition of blood NEU activity. Enhancement of soluble NEU activity in serum decreases the Sia residues from alkaline phosphatase (APL) enzymes, which are involved in the clearance of circulating LPS-phosphate during sepsis (14). 
SARS-CoV-2 infection leads to mild illness in most of the patients, but $\sim 20 \%$ of them progress to severe disease with many characteristics resembling sepsis, including acute respiratory distress syndrome (ARDS), cytokine storm, and neutrophil dysregulation (38, 62-64). The transcriptional programs found in neutrophil subsets from blood and lungs of severe COVID-19 patients are related to cell dysfunction, coagulation, and NETs formation $(39,43)$. We observed that blood neutrophils from severe COVID-19 are highly activated as demonstrated by reduced CD62L expression and increase of CD66b expression, as previously reported (43). We now add new information by showing that NEU1 is highly expressed in the respiratory tract of moderate and critical COVID-19 patients and blood neutrophils from severe, but not convalescent, COVID-19 patients with reduced surface levels of $\alpha 2-3$ and $\alpha 2-6-S i a$, suggesting a relevant role of NEU for COVID-19 pathology. More importantly, both the NEU inhibitors Oseltamivir and Zanamivir, increased the sialic acid content and rewired the overactivation of neutrophils from severe COVID-19 patients. We speculate that the addition of NEUs competitive inhibitors allowed the endogenous sialyltransferases to restore sialyl residues on surface glycoconjugates. Fast changes of surface sialic acid levels by sialidases and sialyltransferases seems to be an important mechanism to control neutrophil response (56). In neutrophils from healthy donors or COVID-19 convalescent patients, Oseltamivir and Zanamivir did not interfere in resting state and had no effect on sialic acid content, suggesting that NEU has a low effect on surface Sia turnover on non-activated neutrophils. How neutrophils are activated and the role of NEU in this process remains to be defined in COVID-19, nevertheless, recent evidence showed that neutrophils could be directly activated by SARS-CoV-2 (2), cytokines (65) and alarmins $(39,43)$, such as calprotectin (39), a TLR4 ligand (66). Furthermore, we now suggest that soluble NEU with 
other circulating factors present in plasma from severe COVID-19 patients also accounts for neutrophil activation.

Collectively, this work suggests that host NEU activation leads to shedding of surface sialic acid with consequent neutrophil overstimulation, tissue damage, and high mortality rates. On the other hand, NEU inhibitors-prevented shedding of sialic acid and regulates neutrophil response, resulting in infection control and high survival rates (working model in Supplementary Fig. 10). Considering that both drugs have a safety profile with few well-known adverse effects, our data suggest Oseltamivir and Zanamivir could be repurposed for the treatment of sepsis or severe infections such as COVID-19. Interestingly, a retrospective single-center cohort study including 1190 patients with COVID-19 in Wuhan, China, showed that administration of Oseltamivir was associated with a decreased risk of death in severe patients (67). Nevertheless, randomized clinical trials with NEU inhibitors in sepsis and COVID-19 are required to directly explore this hypothesis.

\section{Acknowledgments}

We thank Universidade Federal de Santa Catarina (UFSC), the Laboratório Multiusuário de Estudos em Biologia (LAMEB/UFSC), CAPES/PrInt, CNPq and Le programme de bourses d'excellence Eiffel (Campus France - Ministère de l'Europe et des Affaires étrangères) for the support. 


\section{REFERENCES}

1. Mócsai A. Diverse novel functions of neutrophils in immunity, inflammation, and beyond. J Exp Med 2013;210:1283-1299.

2. Veras FP, Pontelli MC, Silva CM, Toller-Kawahisa JE, de Lima M, Nascimento DC, Schneider AH, Caetité D, Tavares LA, Paiva IM, Rosales R, Colón D, Martins R, Castro IA, Almeida GM, Lopes MIF, Benatti MN, Bonjorno LP, Giannini MC, Luppino-Assad R, Almeida SL, Vilar F, Santana R, Bollela VR, Auxiliadora-Martins M, Borges M, Miranda CH, Pazin-Filho A, da Silva LLP, et al. SARS-CoV-2-triggered neutrophil extracellular traps mediate COVID-19 pathology. J Exp Med 2020;217.:

3. Alves-Filho JC, Spiller F, Cunha FQ. Neutrophil paralysis in sepsis. Shock 2010;34 Suppl 1:15-21.

4. Segal AW. HOW NEUTROPHILS KILL MICROBES. Annual Review of Immunology 2005;

5. Steevels TAM, Meyaard L. Immune inhibitory receptors: essential regulators of phagocyte function. Eur J Immunol 2011;41:575-587.

6. Macauley MS, Crocker PR, Paulson JC. Siglec-mediated regulation of immune cell function in disease. Nat Rev Immunol 2014;14:653-666.

7. Varki A. Sialic acids in human health and disease. Trends in Molecular Medicine 2008; 8. Lipničanová S, Chmelová D, Ondrejovič M, Frecer V, Miertuš S. Diversity of sialidases found in the human body - A review. Int J Biol Macromol 2020;148:857-868.

9. Chang Y-C, Uchiyama S, Varki A, Nizet V. Leukocyte inflammatory responses provoked by pneumococcal sialidase. MBio 2012;3:

10. Suzuki $\mathrm{H}$, Kurita $\mathrm{T}$, Kakinuma K. Effects of neuraminidase on $\mathrm{O} 2$ consumption and release of $\mathrm{O} 2$ and $\mathrm{H} 2 \mathrm{O} 2$ from phagocytosing human polymorphonuclear leukocytes. Blood 1982;60:446-453. 
11. Arora DJ, Henrichon M. Superoxide anion production in influenza protein-activated NADPH oxidase of human polymorphonuclear leukocytes. J Infect Dis 1994;169:1129-1133.

12. Henricks PA, van Erne-van der Tol ME, Verhoef J. Partial removal of sialic acid enhances phagocytosis and the generation of superoxide and chemiluminescence by polymorphonuclear leukocytes. J Immunol 1982;129:745-750.

13. Amith SR, Jayanth P, Franchuk S, Siddiqui S, Seyrantepe V, Gee K, Basta S, Beyaert R, Pshezhetsky AV, Szewczuk MR. Dependence of pathogen molecule-induced toll-like receptor activation and cell function on Neu1 sialidase. Glycoconj J 2009;26:1197-1212. 14. Yang WH, Heithoff DM, Aziz PV, Haslund-Gourley B, Westman JS, Narisawa S, Pinkerton AB, Millán JL, Nizet V, Mahan MJ, Marth JD. Accelerated Aging and Clearance of Host Anti-inflammatory Enzymes by Discrete Pathogens Fuels Sepsis. Cell Host Microbe 2018;24:500-513.e5.

15. Chen G-Y, Brown NK, Wu W, Khedri Z, Yu H, Chen X, van de Vlekkert D, D'Azzo A, Zheng P, Liu Y. Broad and direct interaction between TLR and Siglec families of pattern recognition receptors and its regulation by Neu1. Elife 2014;3:e04066.

16. Mills EL, Debets-Ossenkopp Y, Verbrugh HA, Verhoef J. Initiation of the respiratory burst of human neutrophils by influenza virus. Infection and Immunity 1981;

17. Kilkenny C, Browne WJ, Cuthill IC, Emerson M, Altman DG. Improving bioscience research reporting: the ARRIVE guidelines for reporting animal research. Osteoarthritis Cartilage 2012;20:256-260.

18. Knibbs RN, Goldstein IJ, Ratcliffe RM, Shibuya N. Characterization of the carbohydrate binding specificity of the leukoagglutinating lectin from Maackia amurensis. Comparison with other sialic acid-specific lectins. Journal of Biological Chemistry 1991;

19. Movsisyan LD, Macauley MS. Structural advances of Siglecs: insight into synthetic glycan ligands for immunomodulation. Org Biomol Chem 2020;18:5784-5797. 
20. Varki A, Gagneux P. Multifarious roles of sialic acids in immunity. Ann N Y Acad Sci 2012;1253:16-36.

21. Cross AS, Wright DG. Mobilization of sialidase from intracellular stores to the surface of human neutrophils and its role in stimulated adhesion responses of these cells. J Clin Invest 1991;88:2067-2076.

22. Schmidt T, Zündorf J, Grüger T, Brandenburg K, Reiners A-L, Zinserling J, Schnitzler N. CD66b overexpression and homotypic aggregation of human peripheral blood neutrophils after activation by a gram-positive stimulus. J Leukoc Biol 2012;91:791-802.

23. Kishimoto TK, Jutila MA, Berg EL, Butcher EC. Neutrophil Mac-1 and MEL-14 adhesion proteins inversely regulated by chemotactic factors. Science 1989;245:1238-1241.

24. Jutila MA, Rott L, Berg EL, Butcher EC. Function and regulation of the neutrophil MEL14 antigen in vivo: comparison with LFA-1 and MAC-1. J Immunol 1989;143:3318-3324.

25. Amith SR, Jayanth P, Franchuk S, Finlay T, Seyrantepe V, Beyaert R, Pshezhetsky AV, Szewczuk MR. Neu1 desialylation of sialyl alpha-2,3-linked beta-galactosyl residues of TOLLlike receptor 4 is essential for receptor activation and cellular signaling. Cell Signal $2010 ; 22: 314-324$.

26. Mittal M, Siddiqui MR, Tran K, Reddy SP, Malik AB. Reactive oxygen species in inflammation and tissue injury. Antioxid Redox Signal 2014;20:1126-1167.

27. Sônego F, Castanheira FVES, Ferreira RG, Kanashiro A, Leite CAVG, Nascimento DC, Colón DF, Borges V de F, Alves-Filho JC, Cunha FQ. Paradoxical Roles of the Neutrophil in Sepsis: Protective and Deleterious. Front Immunol 2016;7:155.

28. Spiller F, Orrico MIL, Nascimento DC, Czaikoski PG, Souto FO, Alves-Filho JC, Freitas A, Carlos D, Montenegro MF, Neto AF, Ferreira SH, Rossi MA, Hothersall JS, Assreuy J, Cunha FQ. Hydrogen sulfide improves neutrophil migration and survival in sepsis via K+ATP channel activation. Am J Respir Crit Care Med 2010;182:360-368. 
29. Spiller F, Carlos D, Souto FO, de Freitas A, Soares FS, Vieira SM, Paula FJA, Alves-

Filho JC, Cunha FQ. a1-Acid glycoprotein decreases neutrophil migration and increases susceptibility to sepsis in diabetic mice. Diabetes 2012;61:1584-1591.

30. Vimr ER, Troy FA. Identification of an inducible catabolic system for sialic acids (nan) in Escherichia coli. J Bacteriol 1985;164:845-853.

31. Butler CC, van der Velden AW, Bongard E, Saville BR, Holmes J, Coenen S, Cook J, Francis NA, Lewis RJ, Godycki-Cwirko M, Llor C, Chlabicz S, Lionis C, Seifert B, Sundvall P-D, Colliers A, Aabenhus R, Bjerrum L, Jonassen Harbin N, Lindbæk M, Glinz D, Bucher HC, Kovács B, Radzeviciene Jurgute R, Touboul Lundgren P, Little P, Murphy AW, De Sutter A, Openshaw $\mathrm{P}$, et al. Oseltamivir plus usual care versus usual care for influenza-like illness in primary care: an open-label, pragmatic, randomised controlled trial. Lancet 2020;395:42-52.

32. Rittirsch D, Huber-Lang MS, Flierl MA, Ward PA. Immunodesign of experimental sepsis by cecal ligation and puncture. Nat Protoc 2009;4:31-36.

33. Rhodes A, Evans LE, Alhazzani W, Levy MM, Antonelli M, Ferrer R, Kumar A, Sevransky JE, Sprung CL, Nunnally ME, Rochwerg B, Rubenfeld GD, Angus DC, Annane D, Beale RJ, Bellinghan GJ, Bernard GR, Chiche J-D, Coopersmith C, De Backer DP, French CJ, Fujishima S, Gerlach H, Hidalgo JL, Hollenberg SM, Jones AE, Karnad DR, Kleinpell RM, Koh Y, et al. Surviving Sepsis Campaign: International Guidelines for Management of Sepsis and Septic Shock: 2016. Intensive Care Med 2017;43:304-377.

34. Chou EH, Mann S, Hsu T-C, Hsu W-T, Liu CC-Y, Bhakta T, Hassani DM, Lee C-C. Incidence, trends, and outcomes of infection sites among hospitalizations of sepsis: A nationwide study. PLoS One 2020;15:e0227752.

35. Middleton EA, He X-Y, Denorme F, Campbell RA, Ng D, Salvatore SP, Mostyka M, Baxter-Stoltzfus A, Borczuk AC, Loda M, Cody MJ, Manne BK, Portier I, Harris ES, Petrey AC, Beswick EJ, Caulin AF, lovino A, Abegglen LM, Weyrich AS, Rondina MT, Egeblad M, 
Schiffman JD, Yost CC. Neutrophil extracellular traps contribute to immunothrombosis in COVID-19 acute respiratory distress syndrome. Blood 2020;136:1169-1179.

36. Schurink B, Roos E, Radonic T, Barbe E, Bouman CSC, de Boer HH, de Bree GJ, Bulle EB, Aronica EM, Florquin S, Fronczek J, Heunks LMA, de Jong MD, Guo L, du Long R, Lutter R, Molenaar PCG, Neefjes-Borst EA, Niessen HWM, van Noesel CJM, Roelofs JJTH, Snijder EJ, Soer EC, Verheij J, Vlaar APJ, Vos W, van der Wel NN, van der Wal AC, van der Valk P, et al. Viral presence and immunopathology in patients with lethal COVID-19: a prospective autopsy cohort study. Lancet Microbe 2020;1:e290-e299.

37. Huang C, Wang Y, Li X, Ren L, Zhao J, Hu Y, Zhang L, Fan G, Xu J, Gu X, Cheng Z, Yu T, Xia J, Wei Y, Wu W, Xie X, Yin W, Li H, Liu M, Xiao Y, Gao H, Guo L, Xie J, Wang G, Jiang R, Gao Z, Jin Q, Wang J, Cao B. Clinical features of patients infected with 2019 novel coronavirus in Wuhan, China. Lancet 2020;395:497-506.

38. Guan W-J, Ni Z-Y, Hu Y, Liang W-H, Ou C-Q, He J-X, Liu L, Shan H, Lei C-L, Hui DSC, Du B, Li L-J, Zeng G, Yuen K-Y, Chen R-C, Tang C-L, Wang T, Chen P-Y, Xiang J, Li S-Y, Wang J-L, Liang Z-J, Peng Y-X, Wei L, Liu Y, Hu Y-H, Peng P, Wang J-M, Liu J-Y, et al. Clinical Characteristics of Coronavirus Disease 2019 in China. N Engl J Med 2020;382:1708-1720.

39. Silvin A, Chapuis N, Dunsmore G, Goubet A-G, Dubuisson A, Derosa L, Almire C, Hénon C, Kosmider O, Droin N, Rameau P, Catelain C, Alfaro A, Dussiau C, Friedrich C, Sourdeau E, Marin N, Szwebel T-A, Cantin D, Mouthon L, Borderie D, Deloger M, Bredel D, Mouraud S, Drubay D, Andrieu M, Lhonneur A-S, Saada V, Stoclin A, et al. Elevated Calprotectin and Abnormal Myeloid Cell Subsets Discriminate Severe from Mild COVID-19. Cell 2020;182:1401-1418.e18.

40. Wilk AJ, Rustagi A, Zhao NQ, Roque J, Martínez-Colón GJ, McKechnie JL, Ivison GT, Ranganath T, Vergara R, Hollis T, Simpson LJ, Grant P, Subramanian A, Rogers AJ, Blish CA. A single-cell atlas of the peripheral immune response in patients with severe COVID-19. Nat Med 2020;26:1070-1076. 
41. Kuri-Cervantes L, Pampena MB, Meng W, Rosenfeld AM, Ittner CAG, Weisman AR, Agyekum RS, Mathew D, Baxter AE, Vella LA, Kuthuru O, Apostolidis SA, Bershaw L, Dougherty J, Greenplate AR, Pattekar A, Kim J, Han N, Gouma S, Weirick ME, Arevalo CP, Bolton MJ, Goodwin EC, Anderson EM, Hensley SE, Jones TK, Mangalmurti NS, Luning Prak ET, Wherry EJ, et al. Comprehensive mapping of immune perturbations associated with severe COVID-19. Sci Immunol 2020;5.:

42. Chua RL, Lukassen S, Trump S, Hennig BP, Wendisch D, Pott F, Debnath O, Thürmann L, Kurth F, Völker MT, Kazmierski J, Timmermann B, Twardziok S, Schneider S, Machleidt F, Müller-Redetzky H, Maier M, Krannich A, Schmidt S, Balzer F, Liebig J, Loske J, Suttorp N, Eils J, Ishaque N, Liebert UG, von Kalle C, Hocke A, Witzenrath M, et al. COVID-19 severity correlates with airway epithelium-immune cell interactions identified by single-cell analysis. Nat Biotechnol 2020;38:970-979.

43. Schulte-Schrepping J, Reusch N, Paclik D, Baßler K, Schlickeiser S, Zhang B, Krämer B, Krammer T, Brumhard S, Bonaguro L, De Domenico E, Wendisch D, Grasshoff M, Kapellos TS, Beckstette M, Pecht T, Saglam A, Dietrich O, Mei HE, Schulz AR, Conrad C, Kunkel D, Vafadarnejad E, Xu C-J, Horne A, Herbert M, Drews A, Thibeault C, Pfeiffer M, et al. Severe COVID-19 Is Marked by a Dysregulated Myeloid Cell Compartment. Cell 2020;182:1419_ 1440.e23.

44. Leliefeld PHC, Wessels CM, Leenen LPH, Koenderman L, Pillay J. The role of neutrophils in immune dysfunction during severe inflammation. Crit Care 2016;20:73. 45. Smutova V, Albohy A, Pan X, Korchagina E, Miyagi T, Bovin N, Cairo CW, Pshezhetsky AV. Structural basis for substrate specificity of mammalian neuraminidases. PLoS One 2014;9:e106320.

46. Glanz VY, Myasoedova VA, Grechko AV, Orekhov AN. Sialidase activity in human pathologies. Eur J Pharmacol 2019;842:345-350. 
47. Cross AS, Sakarya S, Rifat S, Held TK, Drysdale B-E, Grange PA, Cassels FJ, Wang LX, Stamatos N, Farese A, Casey D, Powell J, Bhattacharjee AK, Kleinberg M, Goldblum SE. Recruitment of murine neutrophils in vivo through endogenous sialidase activity. $J$ Biol Chem 2003;278:4112-4120.

48. Pshezhetsky AV, Hinek A. Where catabolism meets signalling: neuraminidase 1 as a modulator of cell receptors. Glycoconj J 2011;28:441-452.

49. Abdulkhalek S, Amith SR, Franchuk SL, Jayanth P, Guo M, Finlay T, Gilmour A, Guzzo C, Gee K, Beyaert R, Szewczuk MR. Neu1 sialidase and matrix metalloproteinase-9 cross-talk is essential for Toll-like receptor activation and cellular signaling. J Biol Chem 2011;286:3653236549.

50. Feng C, Stamatos NM, Dragan Al, Medvedev A, Whitford M, Zhang L, Song C, Rallabhandi P, Cole L, Nhu QM, Vogel SN, Geddes CD, Cross AS. Sialyl residues modulate LPS-mediated signaling through the Toll-like receptor 4 complex. PLoS One 2012;7:e32359.

51. Blander JM, Medzhitov R. Regulation of phagosome maturation by signals from toll-like receptors. Science 2004;304:1014-1018.

52. Doyle SE, O'Connell RM, Miranda GA, Vaidya SA, Chow EK, Liu PT, Suzuki S, Suzuki N, Modlin RL, Yeh W-C, Lane TF, Cheng G. Toll-like Receptors Induce a Phagocytic Gene Program through p38. Journal of Experimental Medicine 2004;

53. El-Benna J, Dang PM-C, Gougerot-Pocidalo M-A. Priming of the neutrophil NADPH oxidase activation: role of p47phox phosphorylation and NOX2 mobilization to the plasma membrane. Semin Immunopathol 2008;30:279-289.

54. Brinkmann V. Neutrophil Extracellular Traps Kill Bacteria. Science 2004;

55. Böhmer RH, Trinkle LS, Staneck JL. Dose effects of LPS on neutrophils- in a whole blood flow cytometric assay of phagocytosis and oxidative burst. Cytometry 1992; 
56. Rifat S, Kang TJ, Mann D, Zhang L, Puche AC, Stamatos NM, Goldblum SE, Brossmer $\mathrm{R}$, Cross AS. Expression of sialyltransferase activity on intact human neutrophils. J Leukoc Biol 2008;84:1075-1081.

57. Feng C, Zhang L, Almulki L, Faez S, Whitford M, Hafezi-Moghadam A, Cross AS. Endogenous PMN sialidase activity exposes activation epitope on CD11b/CD18 which enhances its binding interaction with ICAM-1. J Leukoc Biol 2011;90:313-321.

58. Sakarya S, Rifat S, Zhou J, Bannerman DD, Stamatos NM, Cross AS, Goldblum SE. Mobilization of neutrophil sialidase activity desialylates the pulmonary vascular endothelial surface and increases resting neutrophil adhesion to and migration across the endothelium. Glycobiology 2004;14:481-494.

59. Petri B, Phillipson M, Kubes $\mathrm{P}$. The physiology of leukocyte recruitment: an in vivo perspective. J Immunol 2008;180:6439-6446.

60. Worthen GS, Schwab B 3rd, Elson EL, Downey GP. Mechanics of stimulated neutrophils: cell stiffening induces retention in capillaries. Science 1989;245:183-186.

61. Sheu C-C, Gong MN, Zhai R, Chen F, Bajwa EK, Clardy PF, Gallagher DC, Thompson BT, Christiani DC. Clinical characteristics and outcomes of sepsis-related vs non-sepsis-related ARDS. Chest 2010;138:559-567.

62. Wang T, Du Z, Zhu F, Cao Z, An Y, Gao Y, Jiang B. Comorbidities and multi-organ injuries in the treatment of COVID-19. Lancet 2020;

63. Wu Z, McGoogan JM. Characteristics of and Important Lessons From the Coronavirus Disease 2019 (COVID-19) Outbreak in China: Summary of a Report of 72314 Cases From the Chinese Center for Disease Control and Prevention. JAMA 2020;323:1239-1242.

64. Hottz ED, Azevedo-Quintanilha IG, Palhinha L, Teixeira L, Barreto EA, Pão CRR, Righy C, Franco S, Souza TML, Kurtz P, Bozza FA, Bozza PT. Platelet activation and plateletmonocyte aggregate formation trigger tissue factor expression in patients with severe COVID19. Blood 2020;136:1330-1341. 
65. Wang J, Jiang M, Chen X, Montaner LJ. Cytokine storm and leukocyte changes in mild versus severe SARS-CoV-2 infection: Review of 3939 COVID-19 patients in China and emerging pathogenesis and therapy concepts. J Leukoc Biol 2020;108:17-41.

66. Vogl T, Stratis A, Wixler V, Völler T, Thurainayagam S, Jorch SK, Zenker S, Dreiling A, Chakraborty D, Fröhling M, Paruzel P, Wehmeyer C, Hermann S, Papantonopoulou O, Geyer C, Loser K, Schäfers M, Ludwig S, Stoll M, Leanderson T, Schultze JL, König S, Pap T, Roth J. Autoinhibitory regulation of S100A8/S100A9 alarmin activity locally restricts sterile inflammation. J Clin Invest 2018;128:1852-1866.

67. Liu J, Zhang S, Wu Z, Shang Y, Dong X, Li G, Zhang L, Chen Y, Ye X, Du H, Liu Y, Wang T, Huang S, Chen L, Wen Z, Qu J, Chen D. Clinical outcomes of COVID-19 in Wuhan, China: a large cohort study. Ann Intensive Care 2020;10:99. 
Figures and Figure Legends

A

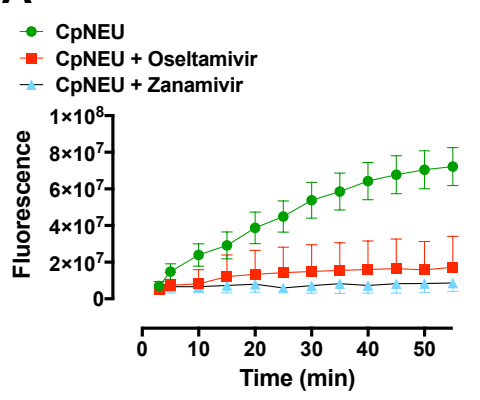

E

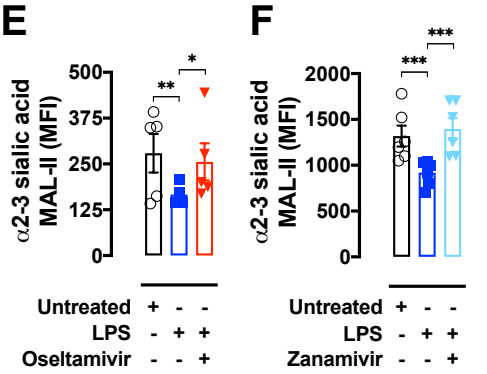

B

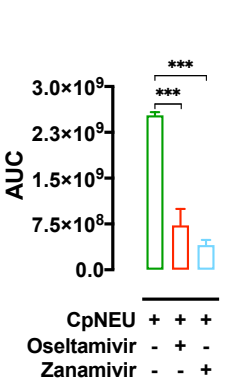

C
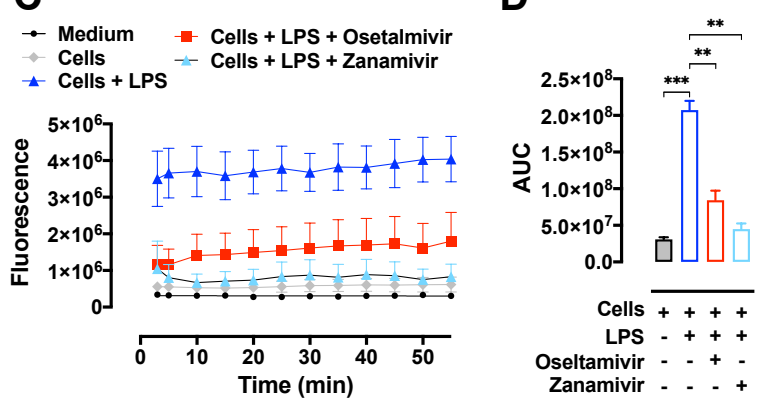
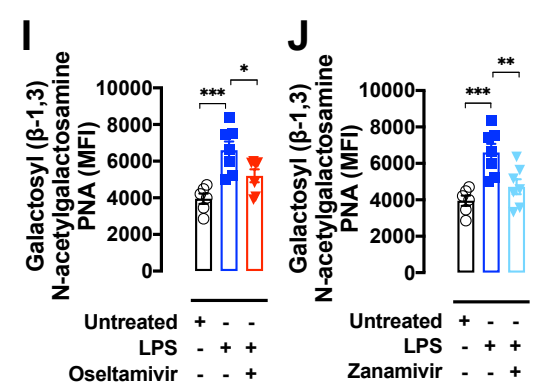
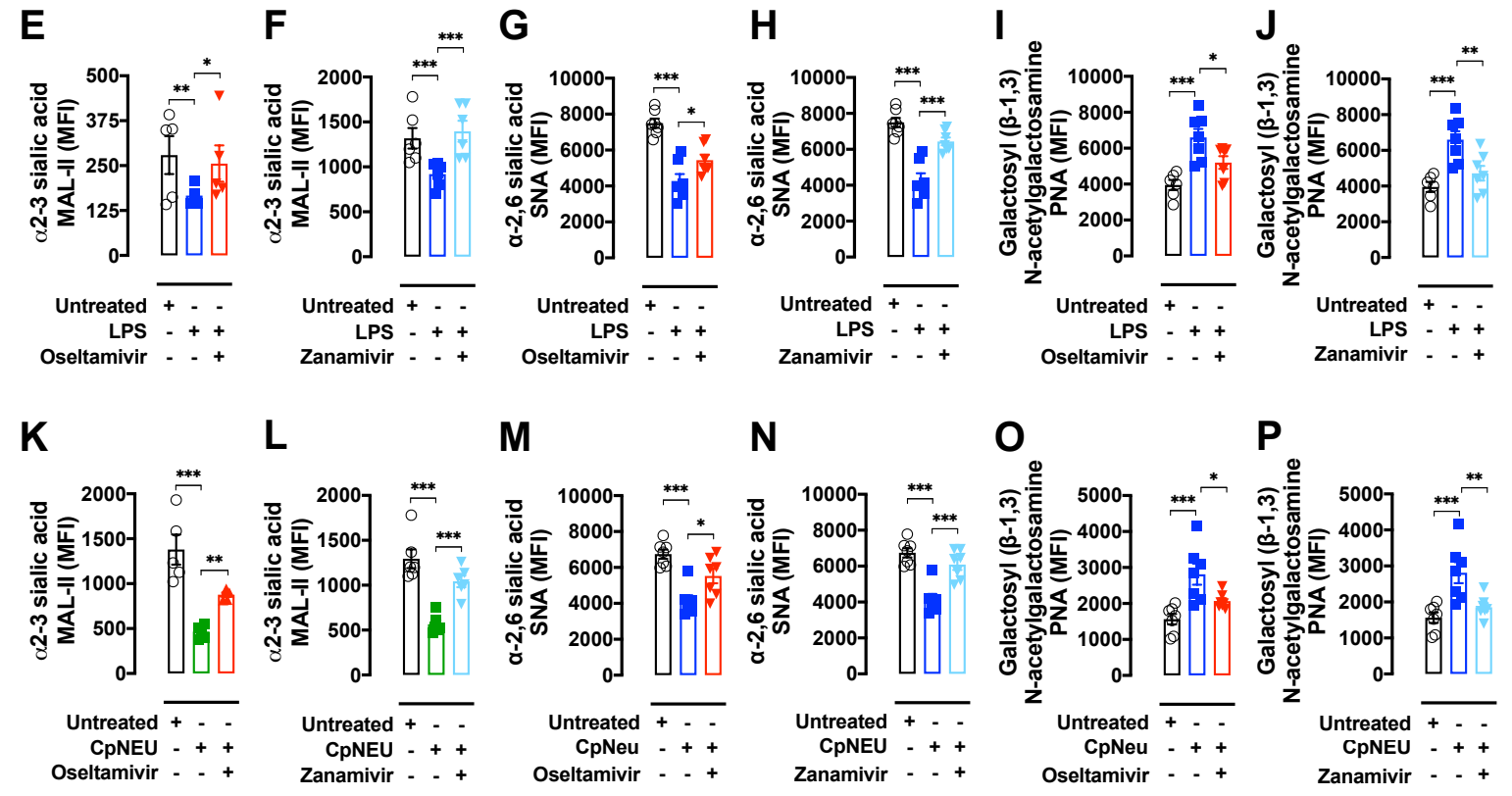

Figure 1. LPS stimulates NEU activity in human leukocytes. Neuraminidase isolated from Clostridium perfringens (CpNEU) was used to validate the NEU activity assay. CpNEU (0.012 UI) was added in a 96-well flat-bottom dark plate on ice in the presence or absence of Oseltamivir phosphate $(100 \mu \mathrm{M})$ or Zanamivir $(30 \mu \mathrm{M})$. Next, the substrate 4-MU-NANA $(0.025 \mathrm{mM})$ was added and the fluorescent substrate was read 3 min after at $37^{\circ} \mathrm{C}(\mathbf{A})$. The area under the curve (AUC) values are shown in $\mathbf{B}$. Total leukocytes resuspended in HBSS were added in a plate on ice and 4-MU-NANA substrate (0.025 $\mathrm{mM}$ ) was added followed by the addition of medium, LPS $(1 \mu \mathrm{g} / \mathrm{mL})$, LPS plus Oseltamivir $(100 \mu \mathrm{M})$ or LPS plus Zanamivir $(30 \mu \mathrm{M})$. The fluorescent substrate was read 3 min after 
at $37^{\circ} \mathrm{C}(\mathbf{C})$. Raw data were subtracted from the control group containing only HBSS (medium) and expressed as AUC values (D). Whole blood containing $1 \times 10^{6}$ leukocytes from healthy donors were stimulated or not with LPS $\left(1 \mu \mathrm{g} / \mathrm{mL}, 90 \mathrm{~min}, 37^{\circ} \mathrm{C}, 5 \% \mathrm{CO}_{2}\right)$, LPS plus Oseltamivir $(100 \mu \mathrm{M})$, or LPS plus Zanamivir $(30 \mu \mathrm{M})$. Total leukocytes $\left(1 \times 10^{6}\right)$ were incubated with $\mathrm{CpNEU}\left(10 \mathrm{mU}, 60 \mathrm{~min}, 37^{\circ} \mathrm{C}, 5 \% \mathrm{CO}_{2}\right)$, CpNEU plus Oseltamivir $(100 \mu \mathrm{M})$, or CpNEU plus Zanamivir $(30 \mu \mathrm{M})$. Leukocytes were stained with MAL-II to detect $\alpha 2-3$ sialic acids (E-F; K-L), with SNA to detect $\alpha 2-6$ sialic acids (G-H; $\mathbf{M}-\mathbf{N})$ or PNA to detect galactosyl $(\beta-1,3) \mathrm{N}$-acetylgalactosamine (I-J; O-P). The MFI was analyzed on $\mathrm{CD}_{66} \mathrm{~b}^{+} / \mathrm{CD} 15^{+}$cells using the gate strategies shown in Supplementary Fig. $1 .{ }^{*} P<$ $0.05 ;{ }^{* *} P<0.01 ;{ }^{* * *} P<0.001$. This figure is representative of three independent experiments $(n=3-6)$ and data are shown as mean \pm SEM. LPS = lipopolysaccharide; $\mathrm{CpNEU}=$ neuraminidase; $\mathrm{MAL}-\mathrm{II}=$ Maackia amurensis lectin II; SNA = Sambucus nigra lectin; PNA = peanut agglutinin . 

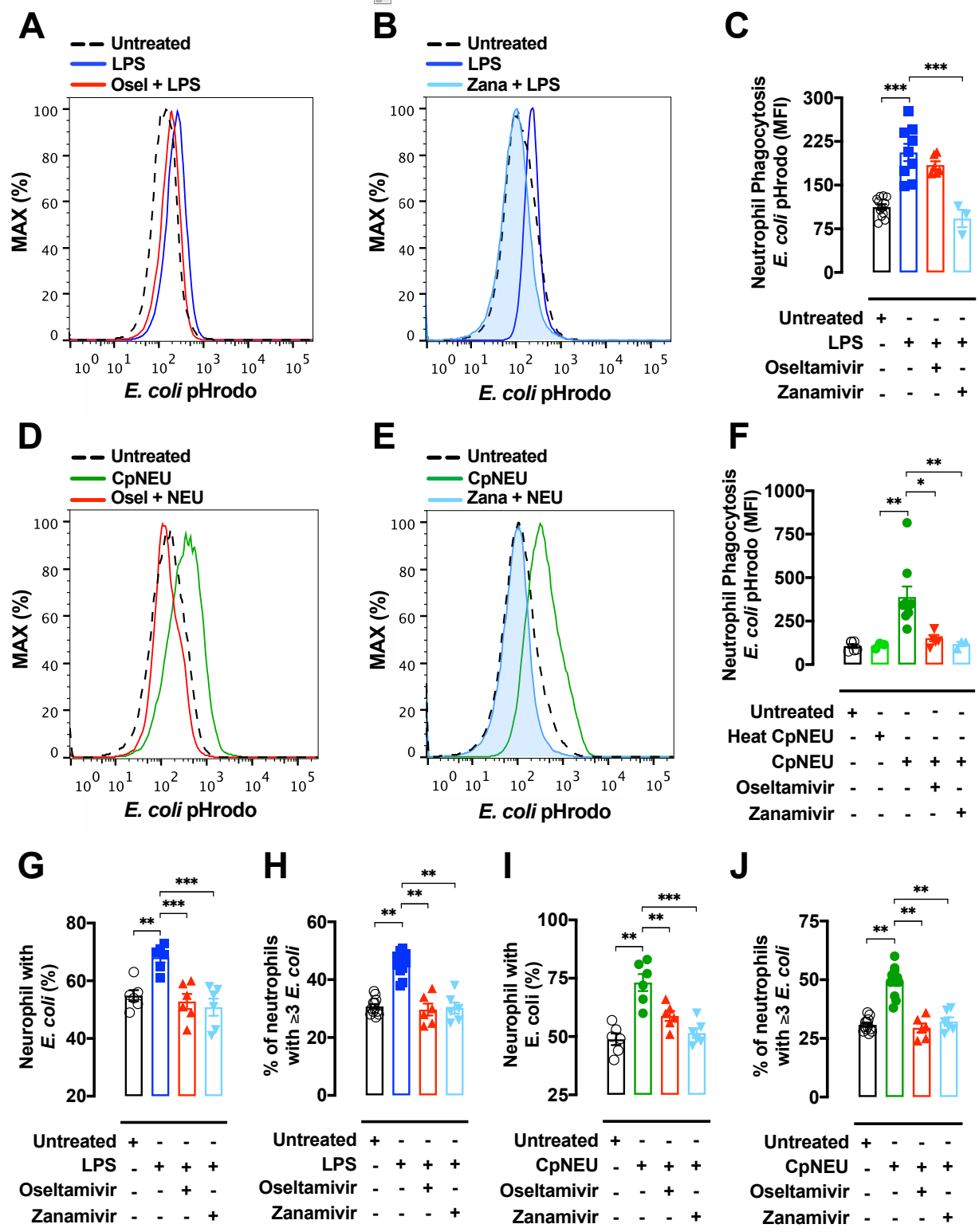

H
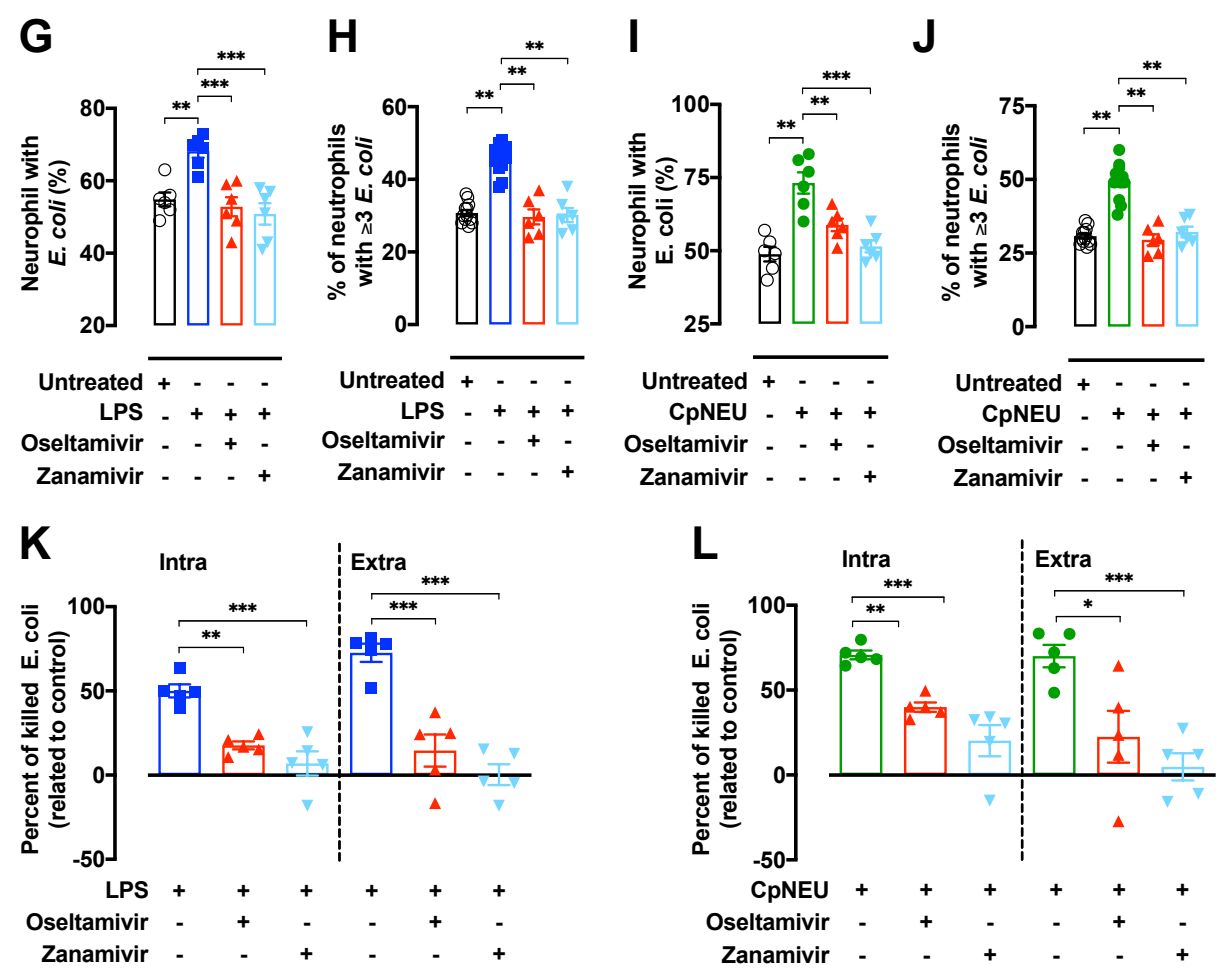

Figure 2. LPS increases phagocytosis and killing of $E$. coli in a NEU-dependent manner. Whole blood from healthy donors containing $1 \times 10^{6}$ leukocytes were exposed 
$\left(37^{\circ} \mathrm{C}, 5 \% \mathrm{CO}_{2}\right)$ or not to LPS $(1 \mu \mathrm{g} / \mathrm{mL}, 90 \mathrm{~min})$, LPS plus Oseltamivir $(100 \mu \mathrm{M})$, or LPS plus Zanamivir $(30 \mu \mathrm{M})(\mathbf{A}-\mathbf{C} ; \mathbf{G}-\mathbf{H} ; \mathbf{K})$. Total leukocytes $\left(1 \times 10^{6}\right)$ were exposed or not to CpNEU (10 mU, $\left.60 \mathrm{~min}, 37^{\circ} \mathrm{C}, 5 \% \mathrm{CO}_{2}\right)$, CpNEU plus Oseltamivir (100 $\left.\mu \mathrm{M}\right)$, or CpNEU plus Zanamivir $(30 \mu \mathrm{M})(\mathbf{D}-\mathbf{F} ; \mathbf{I}-\mathbf{J} ; \mathbf{L})$ and the phagocytosis and killing assays were performed. Leukocytes were incubated with $E$. coli pHrodo BioParticles $®(100 \mu \mathrm{g} / \mathrm{mL})$ for 60 min at $37^{\circ} \mathrm{C}$ to assess phagocytosis in viable $\mathrm{CD} 66 \mathrm{~b}^{+} / \mathrm{CD} 15^{+}$cells $(\mathbf{A}-\mathbf{F})$ (as gated in Supplementary Fig. 1). Live E. coli was used to evaluate phagocytosis by light microscopy or to assess the killing by leukocytes. Cells were stimulated as described above and 1 $\times 10^{6}$ leukocytes were incubated at $37{ }^{\circ} \mathrm{C}$ with $\mathrm{E}$. coli $\left(1 \times 10^{6} \mathrm{CFU}\right)$ for $90 \mathrm{~min}$ for phagocytosis or for 180 min for killing assays. The percentage of cells with ingested bacteria $(\mathbf{G} ; \mathbf{I})$ and the number of bacterial particles per cell $(\mathbf{H} ; \mathbf{J}, \geq 3$ particles per cell) were evaluated. The killing of $E$. coli was evaluated by spreading $10 \mu \mathrm{L}$ of supernatant (extracellular killing) or $10 \mu \mathrm{L}$ of the intracellular content in agar medium and the CFU were counted. Killing E. coli was expressed as the rate of fold change compared to the unprimed (untreated) cells (L). Symbols represent individual donors and data are shown as mean \pm SEM from pooled data of two to three independent experiments $(n=3-12) .{ }^{*} P$ $<0.05 ;{ }^{* *} P<0.01 ;{ }^{* *} P<0.001$. 

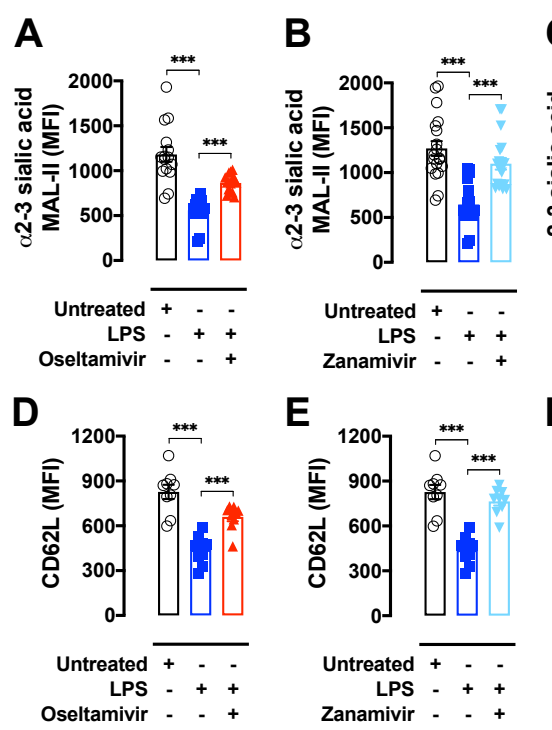

C

$\mathbf{J}$
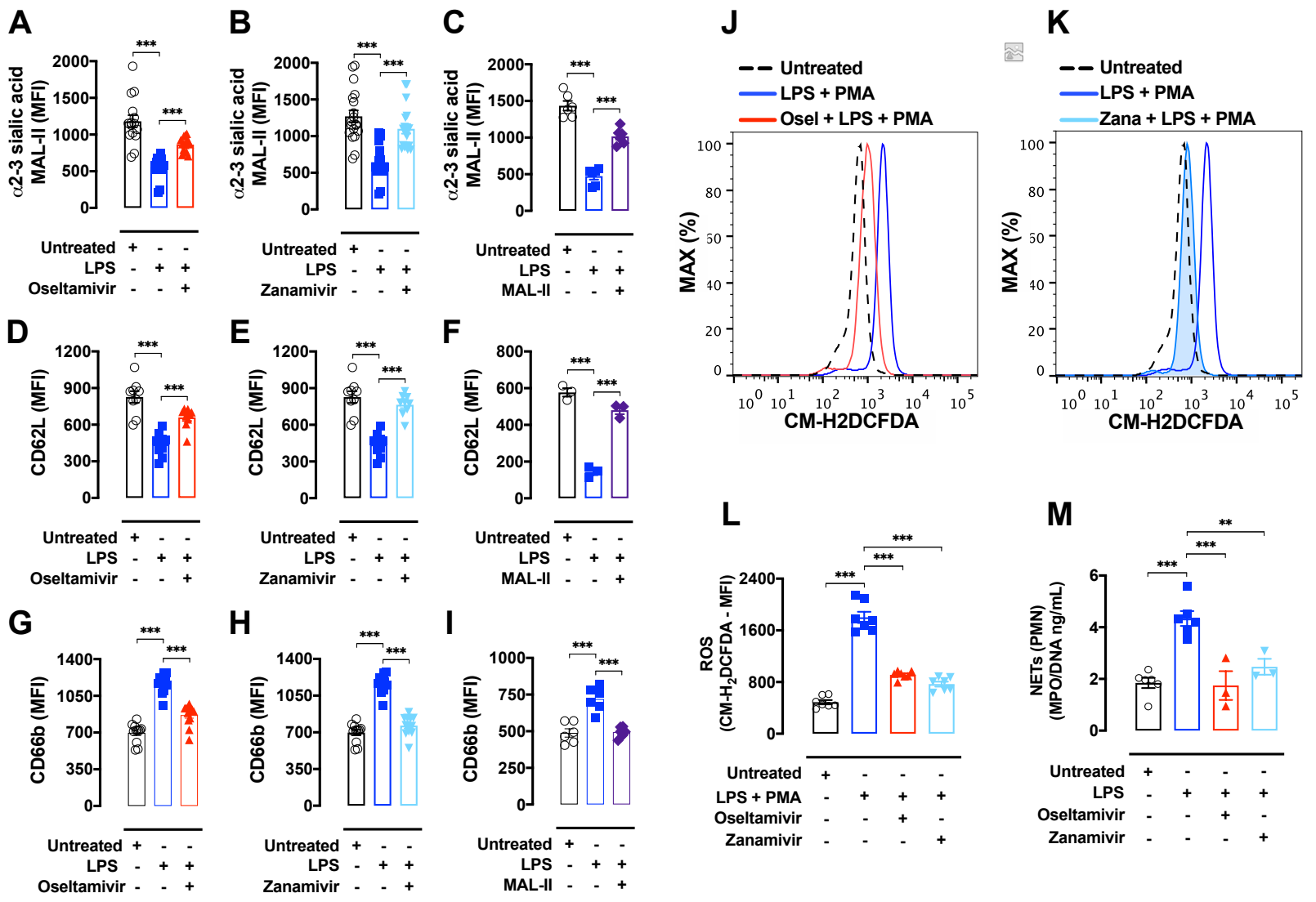

Figure 3. LPS-induced human neutrophil response involves NEU activity. Whole blood from healthy donors containing $1 \times 10^{6}$ leukocytes were stimulated or not with LPS $\left(1 \mu \mathrm{g} / \mathrm{mL}, 90 \mathrm{~min}, 37^{\circ} \mathrm{C}, 5 \% \mathrm{CO}_{2}\right.$ ), LPS plus Oseltamivir (Osel, $\left.100 \mu \mathrm{M}\right)$, LPS plus Zanamivir (Zana, $30 \mu \mathrm{M})$, or LPS plus MAL-II $(1 \mu \mathrm{g} / \mathrm{mL}$, MAL-II promotes steric hindrance at the NEU cleavage site and prevent sialic acid cleavage). Leukocytes were marked with MAL-II (A-C) or with the cell activation markers CD62L (D-F) and CD66b (G-I). After red blood cells lysis leukocytes were incubated with $5 \mu \mathrm{M}$ CM-H2DCFDA fluorescent probe for 15 min. PMA $(10 \mu M)$ was used to stimulate ROS production for $10 \min (J-L)$. Supplementary Fig. 5 showed ROS production in additional control groups. The MFI was analyzed on $\mathrm{CD} 6 \mathrm{~b}^{+}$cells using the gate strategies shown in Supplementary Fig. 1. Isolated neutrophils were treated with Osetamivir $(100 \mu \mathrm{M})$ or Zanamivir $(30 \mu \mathrm{M}) 1 \mathrm{~h}$ 
before the stimulus with LPS $(10 \mu \mathrm{g} / \mathrm{mL})$ for $4 \mathrm{~h}$. The concentration of NETs was evaluated by MPO-DNA PicoGreen assay on supernatants of cells (M). Symbols represent individual donors and data are shown as mean \pm SEM from pooled data of two to three independent experiments $(n=7)$ except for $F$ and $M$ that was made once with $n=3 .{ }^{* *} P$ $<\quad 0.001 ; \quad{ }^{* *} P<0.01 . \quad \mathrm{CM}-\mathrm{H} 2 \mathrm{DCFDA}=$ 5-(and-6)-chloromethyl-2',7'dichlorodihydrofluorescein diacetate, acetyl ester; PMA = phorbol 12-myristate 13acetate; ROS = reactive oxygen species; $\mathrm{NETs}=$ neutrophil extracellular traps; $\mathrm{PMN}=$ polymorphonuclear leukocytes. 


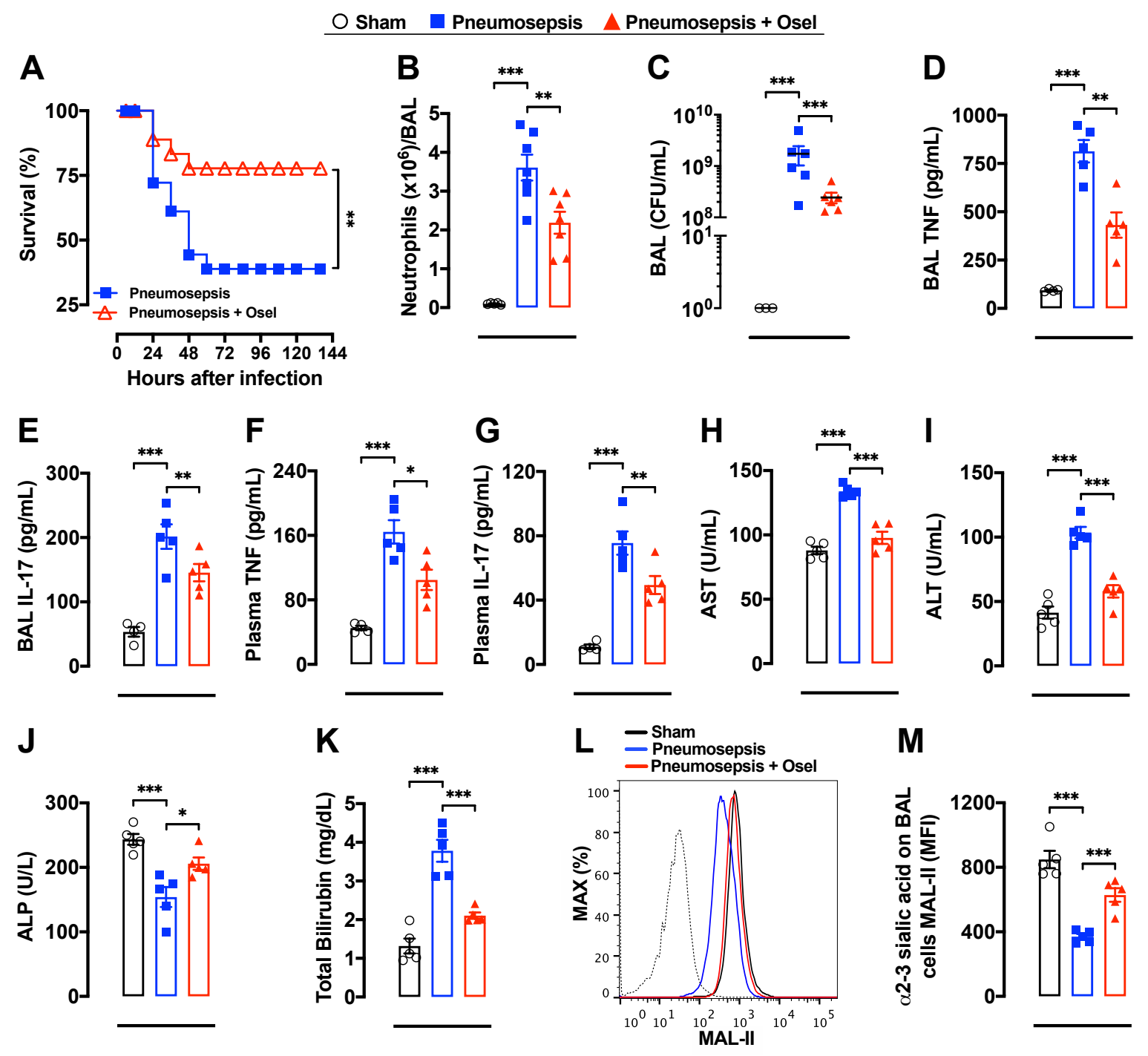

Figure 4. Oseltamivir enhanced mice survival in K. pneumoniae-induced sepsis. Sepsis was induced by intratracheal administration of $K$. pneumoniae and mice were randomly treated (starting $6 \mathrm{hr}$ after infection, $12 / 12 \mathrm{hr}, \mathrm{PO}, \mathrm{n}=20$ ) with saline or Oseltamivir phosphate $(10 \mathrm{mg} / \mathrm{kg}$ ) and survival rates were monitored for $144 \mathrm{hr}(\mathbf{A})$. In similar set of experiments, septic mice $(n=6-7)$ were treated $6 \mathrm{hr}$ after infection with a single dose of Oseltamivir phosphate (10 mg/kg, PO) and mice were euthanized $24 \mathrm{hr}$ after infection to determine the number of neutrophils (B) and CFUs (C), and levels of TNF (D) and IL-17 (E) in BAL. Plasma levels of TNF (F), IL-17 (G), AST (H), ALT (I), ALP 
(J) and total bilirubin (K) were also evaluated $24 \mathrm{hr}$ after infection. The amount of surface $\alpha 2-3$ sialic acids were assessed by MAL-II staining in SSC high $/ \mathrm{Gr}-1^{\text {high }}$ cells in BAL and analyzed by FACS, as shown by the representative histograms (L) and MFI (M); dotted line $=$ unstained cells. The results are expressed as percent of survival, mean or median (only for FACS data) \pm SEM. ${ }^{*} P<0.05 ;{ }^{*} P<0.01$; ${ }^{* \star *} P<0.001$. Sham $=$ sham-operated mice; Osel = Oseltamivir; AST = alanine aminotransferase; $A L T=$ aspartate aminotransferase; ALP = alkaline phosphatase. 
A

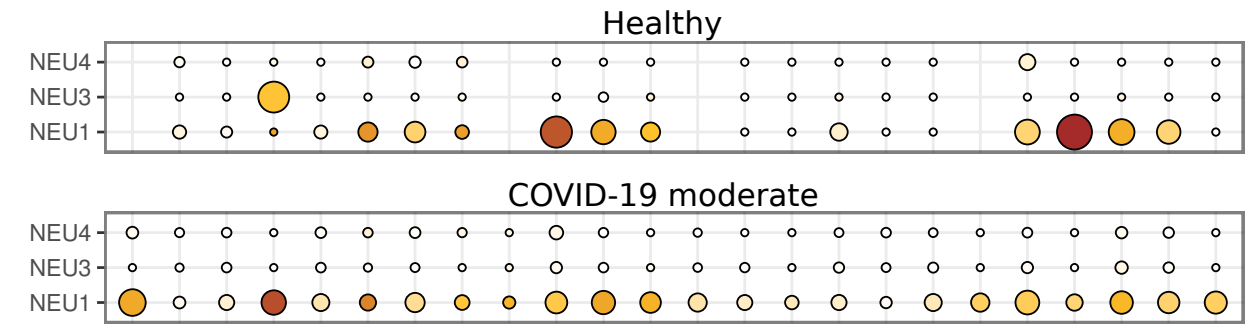

COVID-19 critical

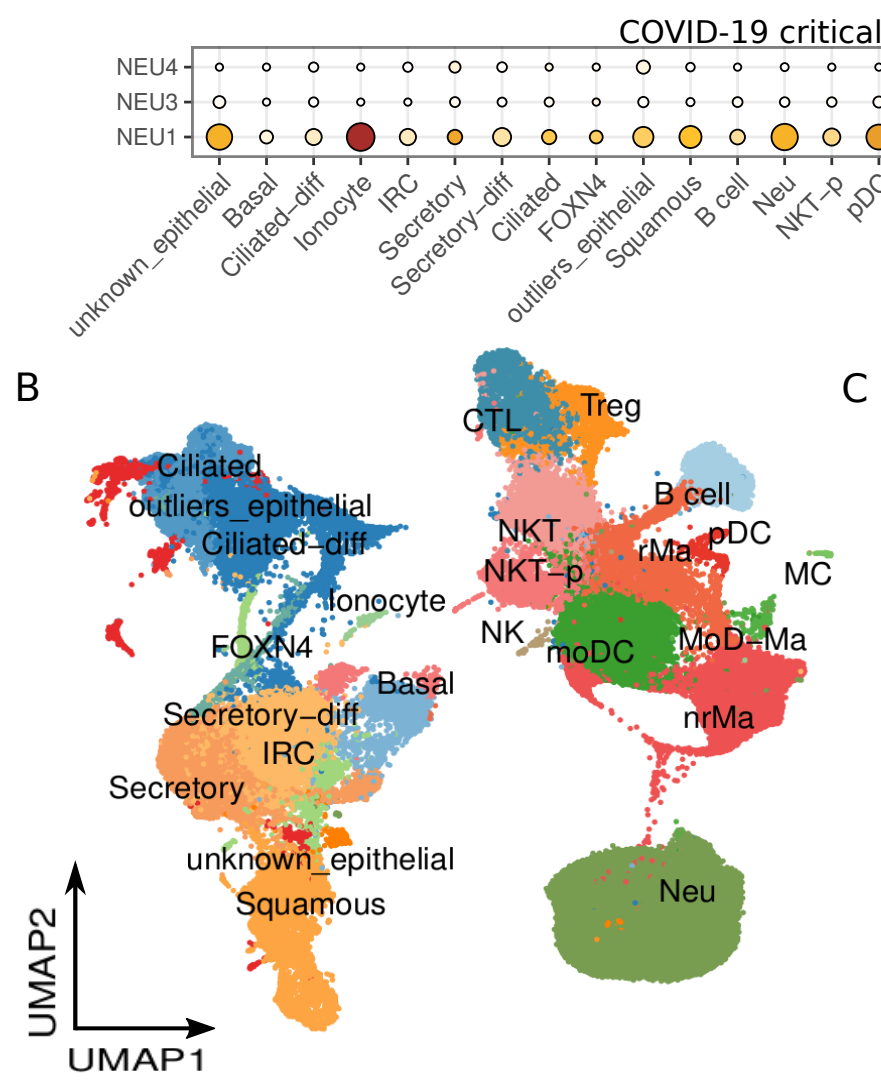

C

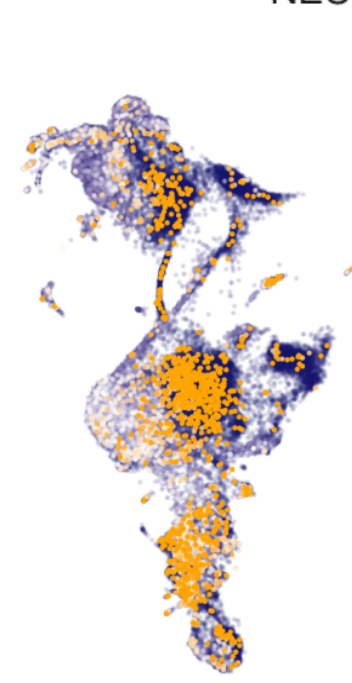

Percentage

$\circ 0$

○ 5

O 10

○ 15

20

25

Average expression

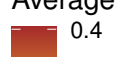

0.3

0.2

0.1

0.0

Figure 5. High expression of NEU1 in cell types from COVID-19 patients. (A) Gene expression of NEU1, NEU3 and NEU4 across cell types in healthy donors and moderate or critical COVID-19 patients. Size of the circle is proportional to the percentage of cells expressing the reported genes at a normalized expression level higher than one. (B) UMAP analysis colored-coded by cell types in nasopharyngeal/pharyngeal swabs samples from healthy donors and COVID-19 patients. (C) Normalized expression of NEU1 overlaid on the UMAP spaces. 


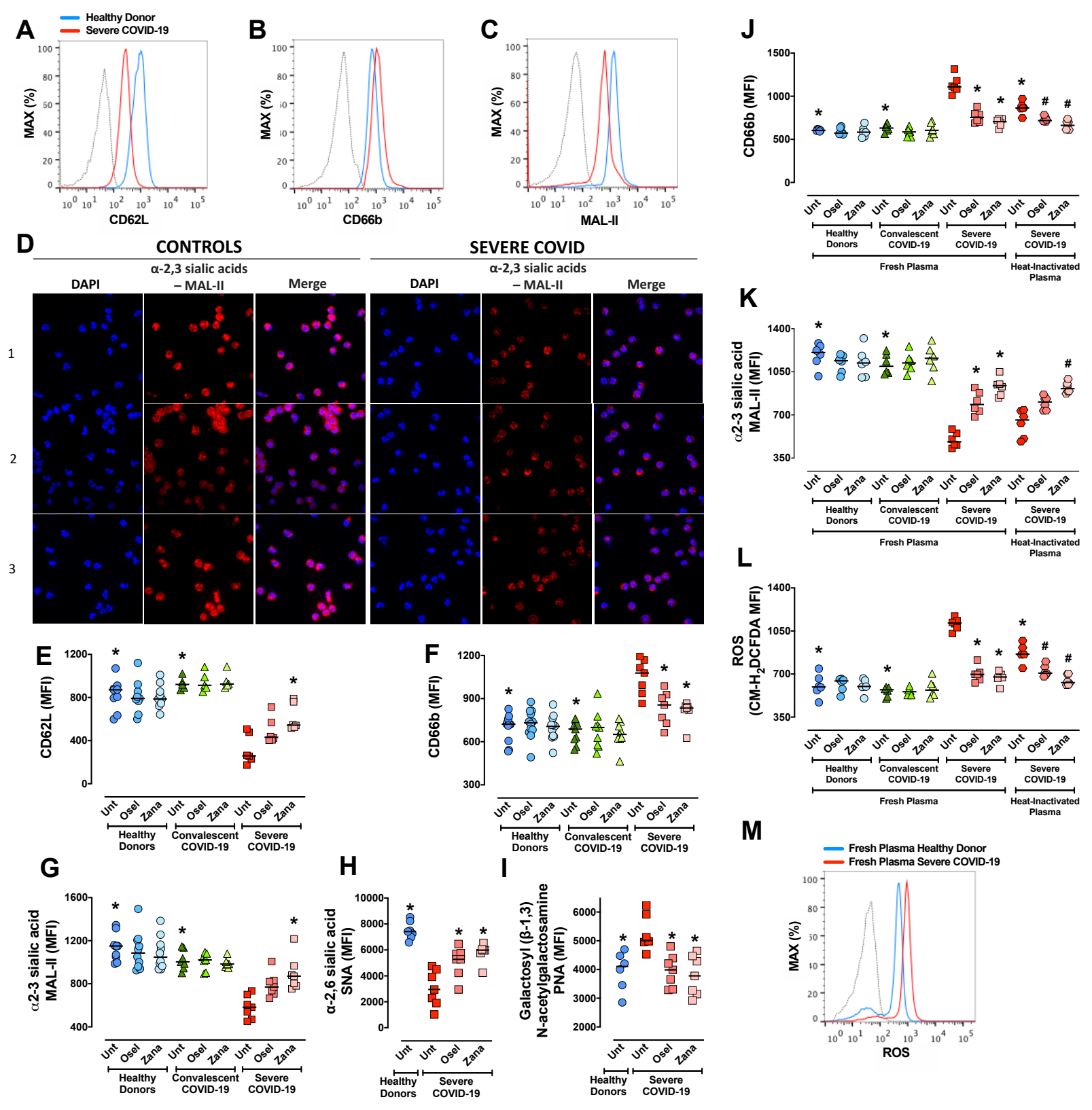

Figure 6. Oseltamivir and Zanamivir decrease neutrophil activation and increase sialic acid levels in active, but not convalescent neutrophils from COVID-19 patients. Whole blood from healthy donors $(n=10)$, severe COVID-19 patients $(n=6)$ or convalescent COVID-19 patients $(n=8)$ were treated or not with Oseltamivir $(100 \mu M)$ or Zanamivir $(30 \mu \mathrm{M})$ and total leukocytes were stained with the cell activation markers 
CD62L (A and E), CD66b (B and F) or the lectins MAL-II (C, D and G), SNA (H) and PNA (I). Immunofluorescence (D) was carried out using biotinylated MAL-II followed by streptavidin Alexa Fluor 555 conjugate. Three different healthy donors (controls) and severe Covid-19 patients were used (magnification 100x). Blood samples from healthy donors $(\mathrm{n}=7)$ were incubated for $2 \mathrm{~h}\left(37^{\circ} \mathrm{C}, 5 \% \mathrm{CO}_{2}\right)$ with $7 \%$ of fresh plasma from healthy donors, severe or convalescent COVID-19 patients or with $7 \%$ of heat-inactivated plasma from severe COVID-19 patients in the presence or absence of Oseltamivir (100 $\mu \mathrm{M})$ or Zanamivir (30 $\mu \mathrm{M})$. Levels of CD66b (J), surface $\alpha 2-3-S i a(M A L-I I)(K)$, and ROS production $(\mathbf{L}, \mathbf{M})$ were assessed by FACS. The MFI was analyzed on $\mathrm{CD} 66 \mathrm{~b}^{+} / \mathrm{CD} 15^{+}$ cells using the gate strategies shown in Supplementary Fig. 1. Symbols represent individual donors and data are shown as scatter dot plot with line at median from pooled data of two to seven independent experiments. The statistical significance between the groups was assessed by ANOVA followed by a multiple comparisons test of Tukey. The accepted level of significance for the test was $P<0.05$. * was significantly different when compared with Untreated Severe COVID-19; \# was significantly different when compared with Untreated Heat-Inactivated Plasma from Severe COVID-19. Osel = Oseltamivir; Zana = Zanamivir 


\section{SUPPLEMENTARY METHODS}

\section{Human blood samples}

Blood was collected from healthy donors (25 - 45 yr old, n=3-12) in endotoxin-free tubes with $\mathrm{K}_{3}$ EDTA (Labor Import, Brasil). All participants gave their written informed consent for blood collection after being informed on procedures. The research protocol followed the World Medical Association Declaration of Helsinki and was approved by the Institutional Review Board of the Federal University of Santa Catarina (CAAE \#82815718.2.0000.0121). Blood samples were also collected from severe COVID-19 ( $n=6)$ or convalescent COVID-19 $(n=8)$ patients (25 to 89 yr old) admitted in the Intensive Care Unit (ICU) or NUPAIVA (Research Center on Asthma and Airway Inflammation) at the UFSC University Hospital from August to October 2020. Severe COVID-19 patients ( $\mathrm{n}=8$ ) (49 to $93 \mathrm{yr}$ old) in the Pneumology Department of Cochin Hospital, Assistance

Publique Hôpitaux de Paris, France (February to April 2021) were also included. Blood samples from sex-matched healthy donors were used as controls. All patients or a close family member gave consent for participation in the study, which was approved by the Institutional Review Board of the UFSC (CAAE \#36944620.5.1001.0121) and the Comité de Protection des Personnes Nord Ouest IV (ID-RCB 2020-A02700-39). Supplementary Table 1 summarizes patients clinical and laboratory records. These samples were used to analyze neutrophil activation, surface sialic acid as well as the effect of plasma under these parameters and ROS production.

\section{Evaluation of neutrophil activation, phagocytosis, killing, ROS, and NETs release}


Whole blood containing $1 \times 10^{6}$ leukocytes were incubated $\left(37^{\circ} \mathrm{C}, 5 \% \mathrm{CO}_{2}\right)$ in the presence or absence of Oseltamivir (100 $\mu \mathrm{M}$, Sigma-Aldrich, San Luis, MO, USA), Zanamivir (30 $\mu \mathrm{M}$, Sigma-Aldrich), LPS (1 $\mathrm{gg} / \mathrm{mL}$, E. coli 0127:b8, Sigma-Aldrich), LPS plus Oseltamivir or LPS plus Zanamivir for $90 \mathrm{~min}$. Concentrations of Oseltamivir (100 $\mu \mathrm{M})$ and Zanamivir $(30 \mu \mathrm{M})$ showed in the experiments here were chosen by the best concentration-effect curves (10-100 $\mu \mathrm{M}$ Oseltavimir and 1-30 $\mu \mathrm{M}$ Zanamivir) with minimum effect on cell apoptosis/necrosis ( $95 \%$ of cell viability) (data not shown). Since plasma is a rich source of glycoconjugates, total leukocytes were used instead of whole blood to evaluate the effect of isolated neuraminidase from Clostridium perfringens (CpNEU) on neutrophils. Red blood cells (RBCs) were lysed by lysis buffer (0.15 M $\mathrm{NH}_{4} \mathrm{Cl}$; $0.1 \mathrm{mM}$ EDTA; $\left.12 \mathrm{mM} \mathrm{Na} \mathrm{HCO}_{3}\right)$ for $7 \mathrm{~min}$, RT, followed by centrifugation $(270 \mathrm{x}$ $\left.\mathrm{g} ; 22^{\circ} \mathrm{C} ; 7 \mathrm{~min}\right)$. Total leukocytes $\left(1 \times 10^{\circ}\right.$ cells) were incubated $\left(37{ }^{\circ} \mathrm{C}, 5 \% \mathrm{CO}_{2}\right)$ in the presence or absence of CpNEU (10 mU, Sigma-Aldrich), CpNEU plus Oseltamivir (100 $\mu \mathrm{M})$ or CpNEU plus Zanamivir $(30 \mu \mathrm{M})$ for $60 \mathrm{~min}$. Next, the following assays were performed. Analysis of neutrophil activation. Leukocytes were then washed and resuspended in flow cytometry (FACS) buffer (2 mM EDTA/PBS). The mix of antibodies against CD66b (G10F5; BioLegend, San Diego, CA, USA), CD62L (DREG-56; BioLegend), CD16 (3G8; BioLegend), isotypes or Maackia amurensis Lectin II biotinylated (MAL-II, Vector Labs, San Diego, CA, USA) coupled to Streptavidin (Biolegend), Sambucus Nigra (Elderberry Bark) Lectin (SNA, Thermofisher), peanut agglutinin from Arachis hypogaea (PNA, Thermofisher) plus human BD Fc Block ${ }^{\mathrm{TM}}$ (BD Pharmingen $^{\mathrm{TM}}$ ) and Fixable Viability Stain (FVS, BD Horizon ${ }^{\mathrm{Tм}}$, San Jose, CA, USA) were added to leukocytes for 30 min at $4{ }^{\circ} \mathrm{C}$. Cells were washed, resuspended in FACS buffer, acquired in a FACSVerse cytometer and analyzed using FlowJo software (FlowJo LLC). 
Approximately 100.000 gated events were acquired in each analysis (Gate strategy shown in Supplementary Fig. 1). Phagocytosis assays. After RBCs lysis, $1 \times 10^{6}$ leukocytes were incubated at $37{ }^{\circ} \mathrm{C}\left(5 \% \mathrm{CO}_{2}\right)$ or at $4{ }^{\circ} \mathrm{C}$ (control) with $100 \mathrm{\mu g} / \mathrm{mL}$ pHrodo $^{\text {TM }}$ Red E. coli BioParticles ${ }^{\circledR}$ (Thermo Fisher, Waltham, MA, USA) for 60 min and the MFI of neutrophils (FVS/CD66b+ cells) with ingested bioparticle was analyzed by FACS. Total leukocytes were also incubated with $1 \times 10^{\circ}$ CFU of live E. coli (ATCC 25922) for $90 \mathrm{~min}\left(37^{\circ} \mathrm{C}, 5 \% \mathrm{CO}_{2}\right.$ ). Next, the cells were washed twice ( $2 \mathrm{mM}$ EDTA/PBS), fixed (FACS buffer/PFA 2\%) and the percentage of neutrophils with bacteria or the percentage of neutrophils with $\geq 3$ bacteria was analyzed by light microscopy using Differential Quick Stain Kit (Laborclin, Brazil). Bacterial killing. Total leukocytes (1 x 10') were incubated $\left(37^{\circ} \mathrm{C}, 5 \% \mathrm{CO}_{2}\right)$ with $1 \times 10^{\circ} \mathrm{CFU}$ of live $\mathrm{E}$. coli for $180 \mathrm{~min}$. The samples were centrifuged $\left(270 \mathrm{~g}, 7 \mathrm{~min}, 4^{\circ} \mathrm{C}\right)$ and $10 \mu \mathrm{L}$ of supernatant were diluted until $10^{\circ}$ and spread onto agar brain-heart infusion (BHI, Kasvi, Brazil) to quantify the viable extracellular bacteria. The pellets were washed twice with PBS/2 mM EDTA (270 g, 7 min, $4{ }^{\circ} \mathrm{C}$ ), the leukocytes were lysed with $2 \%$ Triton-X, washed (PBS, $2000 \mathrm{~g}, 15 \mathrm{~min}, 4$ $\left.{ }^{\circ} \mathrm{C}\right)$, resuspended in PBS and $10 \mu \mathrm{L}$ of samples were diluted until $10^{\circ}$ and spread onto agar $\mathrm{BHI}$. Plates were incubated overnight at $37^{\circ} \mathrm{C}$ and viable bacteria were expressed as mean $\pm \mathrm{SEM}$ of $\mathrm{CFU} / \mathrm{mL}$. ROS assay. After RBCs lysis, $1 \times 10^{\circ}$ leukocytes were incubated at $37{ }^{\circ} \mathrm{C}\left(5 \% \mathrm{CO}_{2}\right)$ with $10 \mu \mathrm{M}$ of cell-permeant $2^{\prime}, 7^{\prime}$-dichlorodihydrofluorescein diacetate (CM-H2DCFDA, ThermoFisher) for 5 min. Next, cells were stimulated or not with phorbol 12-myristate 13-acetate (PMA) for 10 min, fixed, washed twice with PBS/2 mM EDTA ( $\left.270 \mathrm{~g}, 7 \mathrm{~min}, 4{ }^{\circ} \mathrm{C}\right)$ and analyzed by FACS. NETs assay. NETs quantification was performed as previously described (1) on the supernatant of isolated neutrophils. Briefly, an anti-MPO antibody bound to a 96-well flat-bottom plate captured the enzyme 
MPO (5 $\mu \mathrm{g} / \mathrm{ml}$; Abcam), and the amount of DNA bound to the enzyme was quantified using the Quant- iT ${ }^{\text {тм }}$ PicoGreen ${ }^{\circledR}$ kit (Invitrogen, Carlsbad, CA, USA) according to the manufacturer's instructions. Fluorescence intensity (Ex $488 \mathrm{~nm} / \mathrm{Em} 525 \mathrm{~nm}$ ) was quantified in a FlexStation 3 Microplate Reader (Molecular Devices, San Jose, CA, USA). Neutrophil isolation. Human circulating neutrophils were isolated by Percoll density gradients (2). Briefly, four different gradients, $72 \%, 65 \%, 54 \%$, and $45 \%$, were used to isolate human circulating neutrophils. After centrifugation at $600 \mathrm{~g}$ for $30 \mathrm{~min}$ at $4{ }^{\circ} \mathrm{C}$, the cell layer at the $72 \%$ gradient interface was collected as the neutrophil fraction. The erythrocytes were removed by lysis, and cell pellets were resuspended in RPMI 1640 . Isolated neutrophils $\left(1 \times 10^{6} /\right.$ well $)$ were treated with Oseltamivir, Zanamivir or medium 1 h before the stimulus with PMA $(50 \mathrm{nM})$ or LPS $(10 \mu \mathrm{g} / \mathrm{mL})$. After $4 \mathrm{hr}$ of stimuli $\left(37{ }^{\circ} \mathrm{C}\right.$, $5 \% \mathrm{CO}_{2}$ ), the supernatant was collected to measure the levels of NETs.

\section{Neuraminidase kinetics assay}

After RBCs lysis, $0.5 \times 10^{\circ}$ leukocytes were resuspended in HBSS and added to 96-well flat-bottom dark plate (SPL Life Sciences, South Korea) on ice. Then, 4-

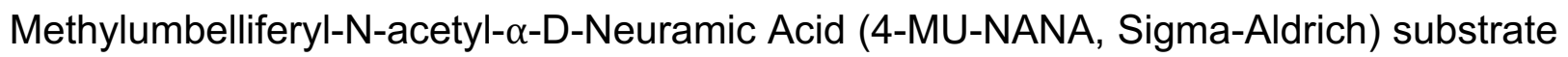
(0.025 mM) was added followed by medium, or LPS $(1 \mu \mathrm{g} / \mathrm{mL})$, LPS plus Oseltamivir (100 $\mu \mathrm{M})$, LPS plus Zanamivir $(30 \mu \mathrm{M})$. CpNEU (10 mU), CpNEU plus Oseltamivir or CpNEU plus Zanamivir were used as positive controls of the assay. The volume was completed to $200 \mu \mathrm{L}$ with HBSS, followed by reading on the Spectramax $($ Paradigm $\AA$ instrument starting $3 \mathrm{~min}$ after and every $5 \mathrm{~min}$ for $55 \mathrm{~min}$ at $37^{\circ} \mathrm{C}$. Sialidase activity was also assessed in heat-inactivated or fresh plasma from severe COVID-19 patients in the presence or absence of Oseltamivir $(100 \mu \mathrm{M})$ or Zanamivir $(30 \mu \mathrm{M})$ using Tecan Infinite 
200 multi-reader. The fluorescent substrate 4-MU-NANA formation was detected at ex $350 \mathrm{~nm} / \mathrm{em} 450 \mathrm{~nm}$.

\section{Immunofluorescence}

Isolated neutrophils $(0.3 \times 10 \%$ slide) were fixed with $2 \%$ paraformaldehyde for 30 min and blocked with 5\% BSA in PBS. Cells were then incubated for 1 hour at $37^{\circ} \mathrm{C}$ with Maackia amurensis Lectin II biotinylated $(15 \mu \mathrm{g} / \mathrm{mL})$ diluted in $1 \%$ BSA/PBS. After washing with PBS, cells were incubated with Streptavidin Alexa Fluor 555 conjugate (1:1000; s32355 Life) for 30 min at $37^{\circ} \mathrm{C}$. Slides were prepared and nuclei stained with Mounting Medium containing DAPI (Sigma Aldrich). Stained cells were examined with a Widefield Zeiss fluorescence microscope, and the images were imported into ImageJ software for analysis.

\section{scRNA-seq Analysis}

Publicly available scRNA-seq data profiling nasopharyngeal or pooled nasopharyngeal/pharyngeal swabs (NSs), bronchial protected specimen brushes (PSBs) and bronchial lavages (BLs) were downloaded from https://figshare.com/articles/COVID-

19 severity correlates_with_airway_epitheliumimmune cell interactions identified by single-cell analysis/12436517. Raw counts data, normalized data and UMAP coordinates generated by the authors of the original publication were imported into CellRouter for downstream analysis (3).

\section{Neutrophil responses with plasma from COVID-19 patients}


Whole blood samples from sex-matched healthy donors $(n=7)$ were incubated for $2 \mathrm{~h}$ (37 ${ }^{\circ} \mathrm{C}, 5 \% \mathrm{CO}_{2}$ ) with $7 \%$ of fresh plasma from healthy donors, severe or convalescent COVID19 patients or heat-inactivated plasma $\left(56^{\circ} \mathrm{C}, 30 \mathrm{~min}\right)$ from severe COVID-19 patients in the presence or absence of Oseltamivir $(100 \mu \mathrm{M})$ or Zanamivir $(30 \mu \mathrm{M})$. Surface levels of a2-3-Sia and CD66b and ROS production were assessed on neutrophils by FACS.

\section{Mice}

The care and treatment of the animals were based on the Guide for the Care and Use of Laboratory Animals (4) and all procedures followed the ARRIVE guidelines and the international principles for laboratory animal studies (5). C57BL/6 (Jackson Laboratory, Bar Harbor, ME, USA) mice (8-10 weeks old) and Swiss mice (10-12 weeks old) were housed in cages at $21 \pm 2^{\circ} \mathrm{C}$ with free access to water and food at the Animal Facility of the Department of Microbiology, Immunology, and Parasitology and Department of Pharmacology from UFSC, respectively. A total of 228 mice were used in this study. Protocols were approved by the Animal Use Ethics Committee of UFSC (CEUA \#8278290818).

\section{E. coli-, Klebsiella pneumoniae- and CLP-induced sepsis}

E. coli (ATCC 25922, Manassas, VA, USA) or K. pneumoniae (ATCC 700603) were used for peritonitis- or pneumonia-induced severe sepsis in mice, as previously described $(6,7)$. Naive mice were intraperitoneal (IP) challenged with $100 \mu \mathrm{L}$ of $1 \mathrm{x}$ $10^{7} \mathrm{CFU}$ of the E. coli suspension. A group of E. coli-septic mice was randomly pretreated ( $2 \mathrm{hr}$ before infection) and post treated by per oral (PO, 12/12 hr) via with 
saline or Oseltamivir phosphate $(10 \mathrm{mg} / \mathrm{kg}$, Eurofarma, Brazil) for 4 days to survival analysis. Another group was pretreated $2 \mathrm{hr}$ before infection with a single dose of Oseltamivir phosphate $(10 \mathrm{mg} / \mathrm{kg}, \mathrm{PO})$ and the pathophysiological response was analyzed at 4 and $6 \mathrm{hr}$ after infection. E. coli-septic mice were also randomly posttreated (6 hr after infection, 12/12 hr) with saline or Oseltamivir phosphate (PO, $10 \mathrm{mg} / \mathrm{kg}$ ) for 4 days to survival analysis. For pneumonia-induced sepsis, mice were anesthetized with isoflurane (3-5 vol\%) and placed in supine position. A small incision was made in the neck where the trachea could be localized and a $K$. pneumoniae suspension ( $4 \times 10^{\circ} \mathrm{CFU} / 50 \mu \mathrm{L}$ of PBS) was injected into the trachea with a sterile 30 gauge needle. Skin was sutured and animals were left for recovery in a warm cage. After $6 \mathrm{hr}$ of infection and then 12/12 hr mice were treated with Oseltamivir phosphate (PO, $10 \mathrm{mg} / \mathrm{kg}$ ) for survival analysis. In another set of experiments, pneumonia was induced and mice were treated $6 \mathrm{hr}$ after infection with a single dose of Oseltamivir phosphate (10 mg/kg, PO) for material collection and analysis of pathophysiological response $24 \mathrm{hr}$ after infection.

Cecal ligation and puncture (CLP)-induced sepsis were performed as previously described (8). Mice were anesthetized with xylazine (2 mg/kg, IP, Syntec, Brazil) followed by isoflurane (3-5 vol\%, BioChimico, Brazil), a $1 \mathrm{~cm}$ midline incision was made in the anterior abdomen, and the cecum was exposed and ligated below the ileocecal junction. The cecum was punctured twice with an 18-gauge needle and gently squeezed to allow its contents to be released through the punctures. Sham-operated (Sham) animals underwent identical laparotomy but without cecal ligation and puncture. The cecum was repositioned in the abdomen, and the peritoneal wall was closed. All animals received 1 $\mathrm{mL}$ of $0.9 \%$ saline subcutaneous (SC) and $100 \mu \mathrm{L}$ of tramadol $(5 \mathrm{mg} / \mathrm{kg}$, SC, Vitalis, 
Brazil) immediately after CLP. CLP-septic mice were randomly treated (starting $6 \mathrm{~h}$ after infection, PO) with $100 \mu \mathrm{L}$ of saline or Oseltamivir phosphate (10 mg/kg, 12/12 hr) for 36 hr. In another set of experiments, CLP mice were randomly IP treated (6 hr after infection, 12/12 hr) during 4 days with $100 \mu \mathrm{L}$ metronidazole $(15 \mathrm{mg} / \mathrm{kg}$, Isofarma, Brazil) plus ceftriaxone (40 mg/kg, Eurofarma, Brazil) and Oseltamivir phosphate $(10 \mathrm{mg} / \mathrm{kg})$ or saline by $\mathrm{PO}$ to survival analysis or treated for $36 \mathrm{hr}$ to analyze the pathophysiological response at $48 \mathrm{hr}$ after CLP.

\section{Neutrophil migration}

The animals were euthanized in a $\mathrm{CO}_{2}$ chamber, the bronchoalveolar lavage (BAL) and peritoneal lavage $(\mathrm{PL})$ were performed and the number of neutrophils was determined at 4 and $6 \mathrm{hr}$ after E. coli, $24 \mathrm{hr}$ after K. pneumoniae infection or $48 \mathrm{hr}$ after CLP surgery, as described ${ }^{28}$. Next, mice were perfused with PBS/EDTA (1 mM) and the lungs were harvested. Lungs were passed through 40- $\mu \mathrm{m}$ nylon cell strainers and single-cell suspensions were centrifuged in 35\% Percoll® solution (315 mOsm/kg, Sigma-Aldrich) for $15 \mathrm{~min}$ at $700 \mathrm{~g}$ to enrich leukocytes populations. Pelleted cells were then collected, and erythrocytes were lysed. Single-cell suspensions from individual mice were determined using a cell counter (Coulter ACT, Beckman Coulter, Brea, CA, USA) or with a haemocytometer. Differential counts were also determined on Cytospin smears stained using Differential Quick Stain Kit (Laborclin, Brazil). Blood samples were collected by heart puncture and tubes containing heparin for further analysis. Neutrophils from LP or BAL were also stained with anti-Ly-6G/Ly-6C (GR-1, RB6-8C5; BioLegend) and MAL-II to be further analyzed by FACS, as previously described. Analysis was carried out in SSC ${ }^{\text {nigh }} / \mathrm{GR}-1^{\text {nigh }}$ cells. 


\section{Bacterial counts}

The bacterial counts were determined as previously described (8). Briefly, the BAL, PL or blood were harvested and $10 \mu \mathrm{L}$ of samples were plated on Muller-Hinton agar dishes (Difco Laboratories, Waltham, MA, USA) and incubated for $24 \mathrm{hr}$ at $37^{\circ} \mathrm{C}$. PL or BAL samples were diluted until $10^{6}$.

\section{ELISA}

TNF (R\&D Systems, Minneapolis, MN, USA) and IL-17 (XpressBio Life Sciences Products, Frederick, MD, USA) levels in plasma, PL or BAL were determined by ELISA kits according to the manufacturer's instructions.

\section{Tissue injury biochemical markers}

Aspartate aminotransferase (AST), alanine aminotransferase (ALT), alkaline phosphatase (ALP) activities, and the levels of total bilirubin were determined in plasma samples by commercial kits (Labtest Diagnóstica, Brazil). The procedures were carried out according to the manufacturer's instructions.

\section{Statistical analysis}

The data are reported as the mean or median \pm SEM of the values obtained from two to seven independent experiments. Each experiment using human samples was performed using three to five samples from healthy donors or one to three samples from severe or convalescent COVID-19 patients. We used five mice per experimental group except for survival analyses in which twelve to twenty mice were used. The mean or median values 
for the different groups were compared by analysis of variance (ANOVA) followed by Dunnett and/or Tukey post-tests. Bacterial counts were analyzed by the Mann-Whitney $U$-test or unpaired $t$-test using a parametric test with Welch's correction. Survival curves were plotted using the Kaplan-Meier method and then compared using the log-rank method and Gehan-Wilcoxon test. Data was analyzed using GraphPad Prism version 8.00 for Mac (GraphPad Software, USA). A $P<0.05$ was considered significant.

Supplementary Table 1. Demographical, clinical and biological characteristics of patients $(n=22)$

\section{Clinical characteristics at inclusion}

Gender (Male/Female) (IQR)) 
Duration of symptoms before inclusion (Days, Median $(\mathrm{IQR}))$

$11(10.25-13.25)$

Dexamethasone treatment duration (Days, Median $(\mathrm{IQR})$ )

\section{Oxygen dependance at inclusion}

Oxygen flow $<3 \mathrm{~L} / \mathrm{mn}$

$1(4.5 \%)$

Oxygen flow $>3 \mathrm{~L} / \mathrm{mn}$

$2(9.1 \%)$

Nasal high flow oxygen (n, (\%))

$5(22.7 \%)$

\section{Overall severity during complete hospitalization}

Maximal oxygen flow during hospitalization $<3 \mathrm{~L} / \mathrm{mn}$

$0(0 \%)$

Maximal oxygen flow during hospitalization $>3 \mathrm{~L} / \mathrm{mn}$

Need for nasal high flow oxygen during hospitalization $(n,(\%))$ 
Complete hospitalization duration (Days, Median (IQR))

$13(8.25-27.25)$

\section{Laboratory data at inclusion}

Hemoglobin (g/dL, Median (IQR))

$13.6(11.38-15.7)$

Hematocrit (\%, Median (IQR))

$40.8(33.4-40.75)$

Leukocytes $\left(/ \mathrm{mm}^{3}\right.$, Median (IQR))

$8102(4070-10660)$

Neutrophils $\left(/ \mathrm{mm}^{3}\right.$, Median (IQR))

$6852(3355-10098)$

Lymphocytes $\left(/ \mathrm{mm}^{3}\right.$, Median (IQR))

$1452(208-3728)$

Monocytes $\left(/ \mathrm{mm}^{3}\right.$, Median (IQR))

$408(168-961)$

Platelets $\left(10^{3} / \mathrm{mm}^{3}\right.$, Median (IQR))

$233(117-436)$

Activated fibrinogen (g/L, Median (IQR))

$5.47(5.125-6.92)$

ELISA D-dimers (ng/mL, Median (IQR))

$1022(559-3123)$

CRP (mg/L, Median (IQR))

$95.3(22-214)$

IQR: interquartile range 


\section{REFERENCES}

1. Czaikoski PG, Mota JMSC, Nascimento DC, Sônego F, Castanheira FV e. S, Melo PH, Scortegagna GT, Silva RL, Barroso-Sousa R, Souto FO, Pazin-Filho A, Figueiredo F, AlvesFilho JC, Cunha FQ. Neutrophil Extracellular Traps Induce Organ Damage during Experimental and Clinical Sepsis. PLoS One 2016;11:e0148142.

2. Mestriner FLAC, Spiller F, Laure HJ, Souto FO, Tavares-Murta BM, Rosa JC, BasileFilho A, Ferreira SH, Greene LJ, Cunha FQ. Acute-phase protein alpha-1-acid glycoprotein mediates neutrophil migration failure in sepsis by a nitric oxide-dependent mechanism. Proc Natl Acad Sci U S A 2007;104:19595-19600.

3. Lummertz da Rocha E, Rowe RG, Lundin V, Malleshaiah M, Jha DK, Rambo CR, Li H, North TE, Collins JJ, Daley GQ. Reconstruction of complex single-cell trajectories using CellRouter. Nat Commun 2018;9:892.

4. National Research Council, Division on Earth and Life Studies, Institute for Laboratory Animal Research, Committee for the Update of the Guide for the Care and Use of Laboratory Animals. Guide for the Care and Use of Laboratory Animals: Eighth Edition. National Academies Press; 2011.

5. Kilkenny C, Browne WJ, Cuthill IC, Emerson M, Altman DG. Improving bioscience research reporting: the ARRIVE guidelines for reporting animal research. Osteoarthritis Cartilage $2012 ; 20: 256-260$.

6. Czaikoski PG, Nascimento DC, Sônego F, de Freitas A, Turato WM, de Carvalho MA, Santos RS, de Oliveira GP, dos Santos Samary C, Tefe-Silva C, Alves-Filho JC, Ferreira SH, Rossi MA, Rocco PRM, Spiller F, Cunha FQ. Heme oxygenase inhibition enhances neutrophil migration into the bronchoalveolar spaces and improves the outcome of murine pneumoniainduced sepsis. Shock 2013;39:389-396. 
bioRxiv preprint doi: https://doi.org/10.1101/2020.11.12.379115; this version posted May 20, 2021. The copyright holder for this preprint (which

was not certified by peer review) is the author/funder, who has granted bioRxiv a license to display the preprint in perpetuity. It is made available under aCC-BY-NC-ND 4.0 International license.

7. Yang WH, Heithoff DM, Aziz PV, Haslund-Gourley B, Westman JS, Narisawa S,

Pinkerton AB, Millán JL, Nizet V, Mahan MJ, Marth JD. Accelerated Aging and Clearance of Host Anti-inflammatory Enzymes by Discrete Pathogens Fuels Sepsis. Cell Host Microbe 2018;24:500-513.e5.

8. Spiller F, Orrico MIL, Nascimento DC, Czaikoski PG, Souto FO, Alves-Filho JC, Freitas A, Carlos D, Montenegro MF, Neto AF, Ferreira SH, Rossi MA, Hothersall JS, Assreuy J, Cunha FQ. Hydrogen sulfide improves neutrophil migration and survival in sepsis via K+ATP channel activation. Am J Respir Crit Care Med 2010;182:360-368. 


\section{Supplementary Figures and Figure Legends}
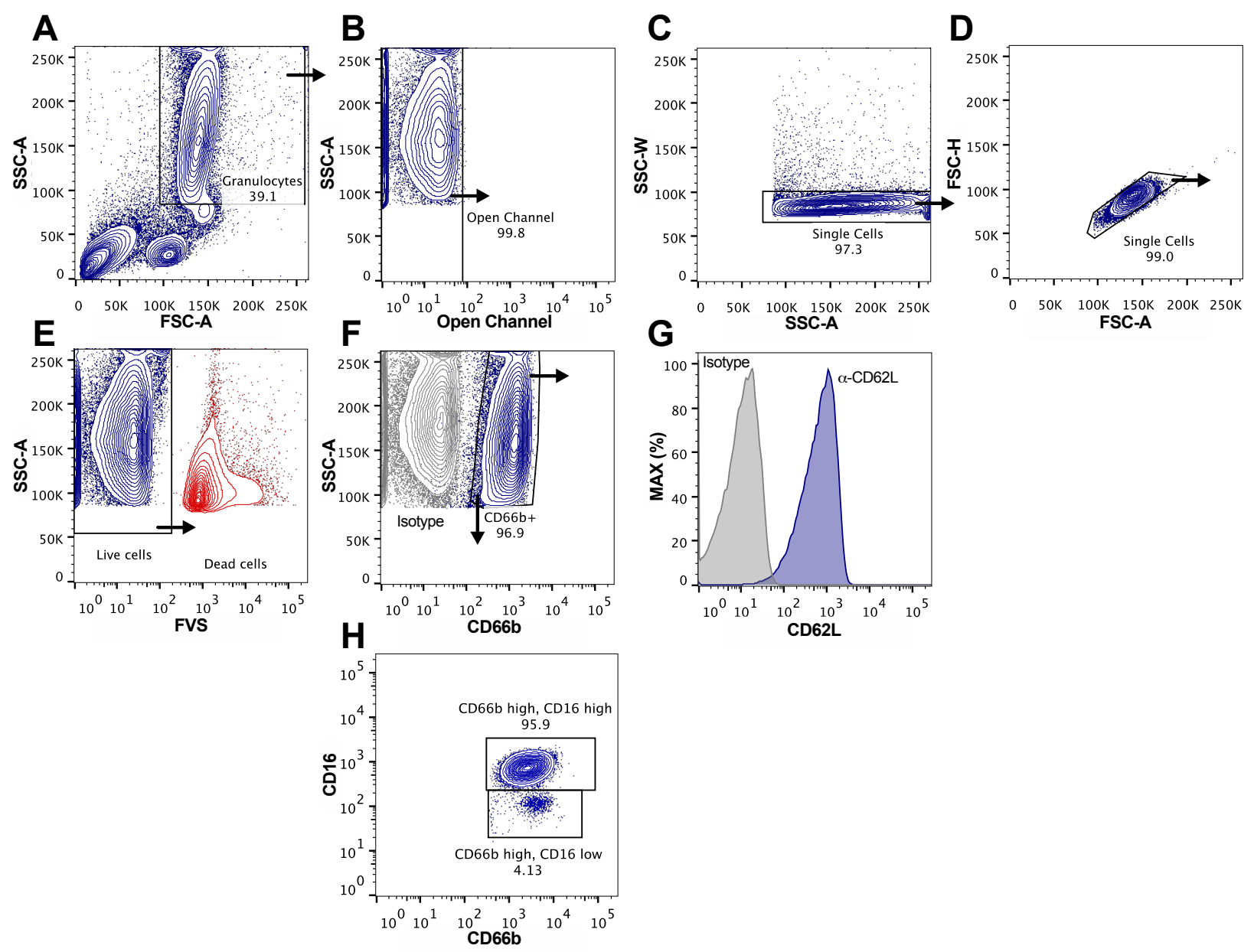

Supplementary Fig. 1. Representative gate strategy used for neutrophils analysis.

A classic forward-scatter (FSC) vs side-scatter (SSC) characteristic dot plot was used to select neutrophils population (A) from peripheral blood collected from healthy donors and patients. Autofluorescent (B) and doublets (C-D) were excluded and live cells were selected $(\mathbf{E})$. CD66 $\mathrm{b}^{+}$positive cells $(\mathbf{F})$ were gated and the MFI of surface markers, such as CD62L (G) were assessed. Around $96 \%$ of $\mathrm{CD} 66 \mathrm{~b}^{+}$cells are mature neutrophils (CD66b-high/CD16-high) and 4\% of $\mathrm{CD} 6 \mathrm{~b}^{+}$cells are CD66b-high/CD16-low, which is suggestive of immature neutrophils or eosinophils $(\mathbf{H})$. Approximately 100.000 gated 
bioRxiv preprint doi: https://doi.org/10.1101/2020.11.12.379115; this version posted May 20, 2021. The copyright holder for this preprint (which

was not certified by peer review) is the author/funder, who has granted bioRxiv a license to display the preprint in perpetuity. It is made available under aCC-BY-NC-ND 4.0 International license.

events were collected in each analysis. The analysis was performed in a FACSVerse using FACSuite software (BD Biosciences) and FlowJo software (FlowJo LLC). 


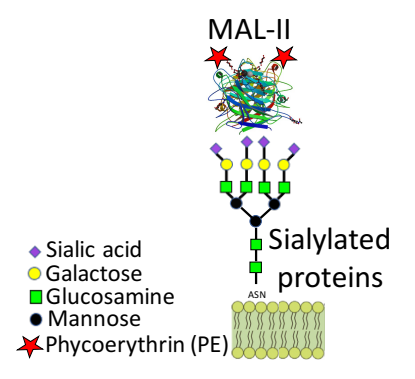

$\alpha$-IgG-Alexa Fluor $^{\circledR} 488$

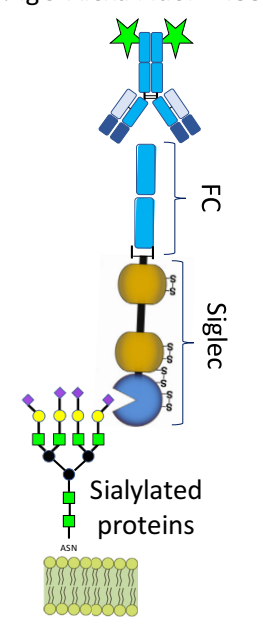

A

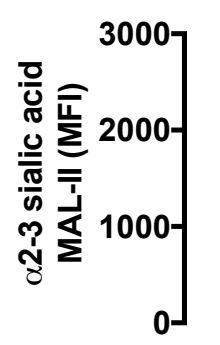

B

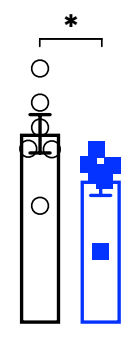

Unt LPS
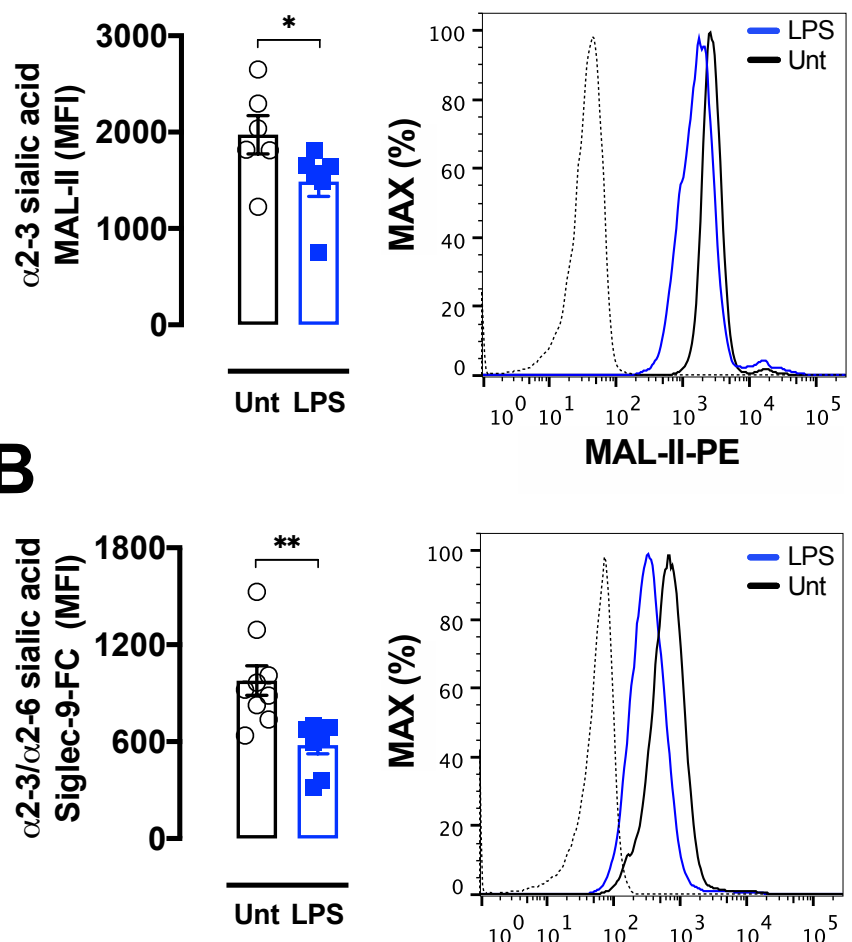

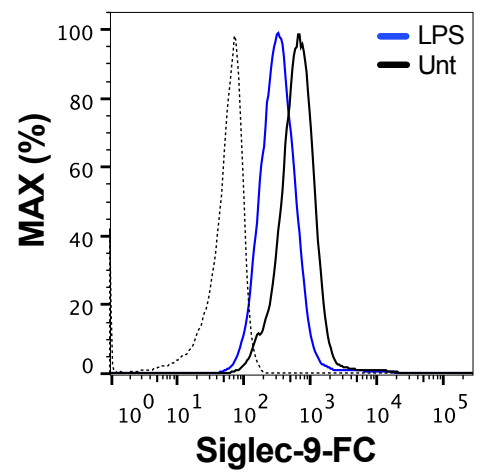

\section{Supplementary Fig. 2. LPS reduces surface $\alpha 2-3$ sialic acids from human}

neutrophils. Whole blood containing $1 \times 10^{6}$ leukocytes from healthy donors were stimulated with $1 \mu \mathrm{g} / \mathrm{mL}$ LPS for $90 \mathrm{~min}$ and $\alpha 2-3$ sialic acid contents were assessed by staining cells with biotinylated Maackia Amurensis Lectin II (MAL-II) (A) followed by streptavidin-phycoerythrin (PE) incubation. Siglec-9 ligands (B) were labeled by incubation of chimeric protein containing Siglec- 9 sialic acid-Ig binding domain fused to a human IgG-Fc portion (Siglec-9-Fc). Siglec-Fc-9 were incubated with a-IgG1-Alexa Fluor 488 before adding the probe to cells. The MFI was analyzed on CD66 ${ }^{+}$cells using the gate strategies shown in Supplementary Fig. 1. ${ }^{*} P<0.05$. Symbols represent individual donors and data are shown as mean \pm SEM from pooled data of two to three independent experiments $(n=6-9)$. Unt $=$ untreated cells; LPS $=$ lipopolysaccharide; dotted line $=$ unstained cells. 


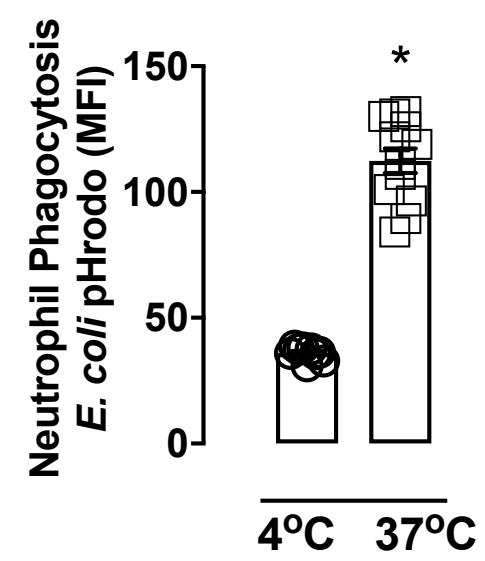

Supplementary Fig. 3. Phagocytosis of E. coli pHrodo bioparticles at $4{ }^{\circ} \mathrm{C}$ and 37

${ }^{\circ} \mathrm{C}$. Total leukocytes $\left(1 \times 10^{6}\right)$ were incubated with $E$. coli pHrodo bioparticles $(100 \mu \mathrm{g} / \mathrm{mL})$ for 60 min at $4^{\circ} \mathrm{C}$ or $37^{\circ} \mathrm{C}$ and the phagocytosis in viable $\mathrm{CD} 66 \mathrm{~b}^{+}$cells was assessed. Symbols represent individual donors and data are shown as mean \pm SEM from pooled data of three to four independent experiments $(n=9-12) .{ }^{*} P<0.001$. 

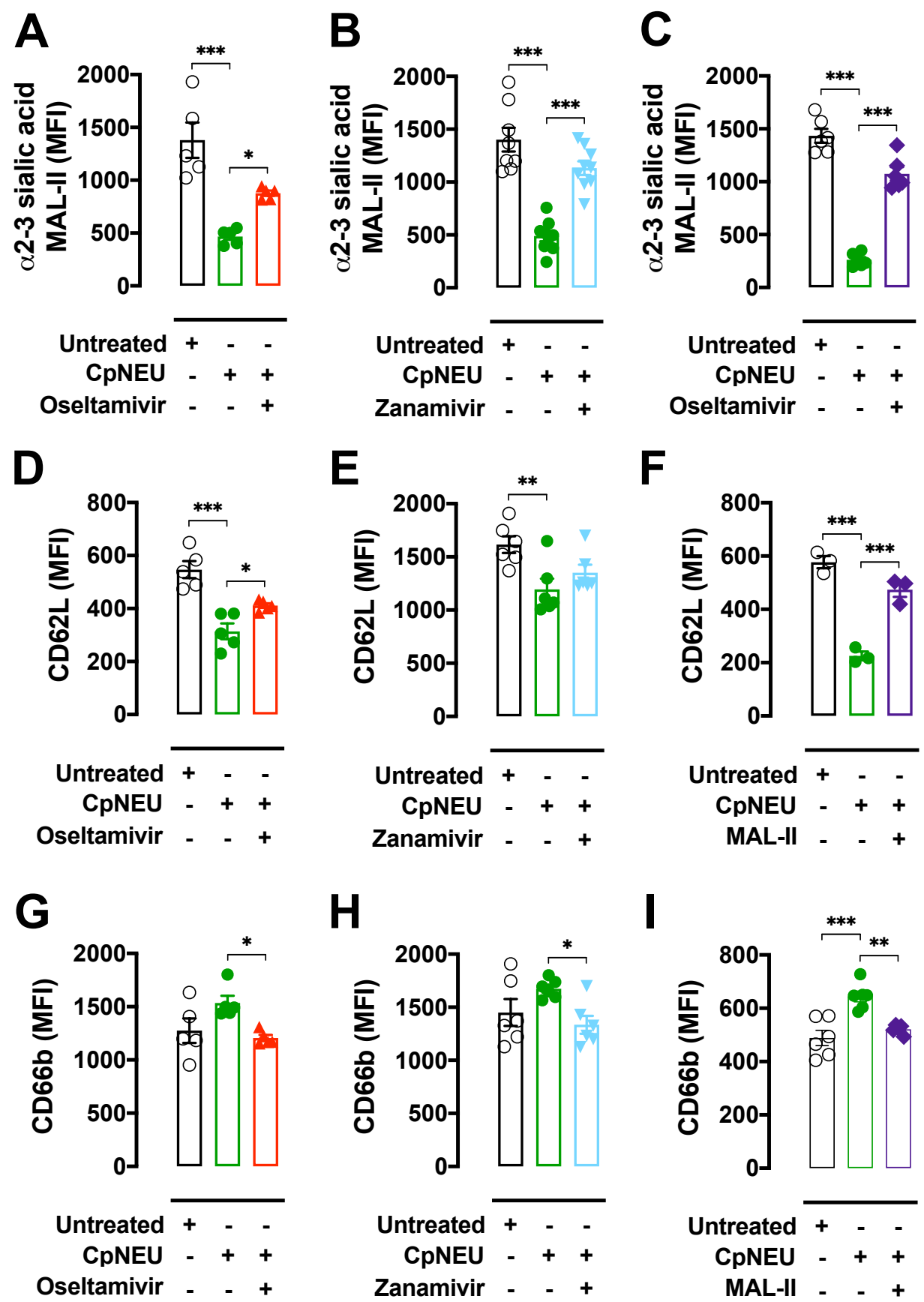

H
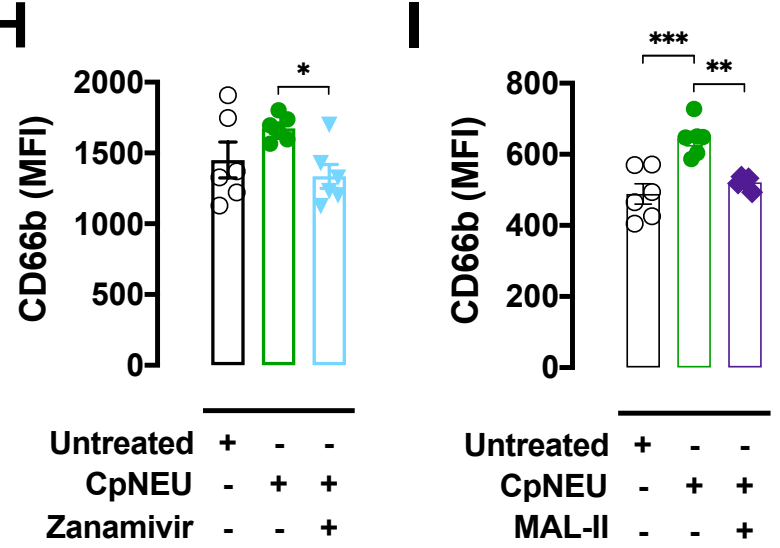

Supplementary Fig. 4. CpNeu-induced human neutrophil activation. Total leukocytes $\left(1 \times 10^{6}\right)$ were incubated or not with CpNEU $\left(10 \mathrm{mU}, 60 \mathrm{~min}, 37{ }^{\circ} \mathrm{C}, 5 \% \mathrm{CO}_{2}\right) \mathrm{CpNEU}$ plus Oseltamivir $(100 \mu \mathrm{M})$, CpNEU plus Zanamivir $(30 \mu \mathrm{M})$ or CpNEU plus MAL-II (1 $\mu \mathrm{g} / \mathrm{mL}$ ). Leukocytes were stained with MAL-II to detect $\alpha 2-3$ sialic acids (A-C) or with cell 
bioRxiv preprint doi: https://doi.org/10.1101/2020.11.12.379115; this version posted May 20, 2021. The copyright holder for this preprint (which was not certified by peer review) is the author/funder, who has granted bioRxiv a license to display the preprint in perpetuity. It is made available under aCC-BY-NC-ND 4.0 International license.

activation markers CD62L (D-F) and CD66b (G-I). The MFI was analyzed on CD66b cells. Symbols represent individual donors and data are shown as mean \pm SEM from pooled data of two to three independent experiments $(n=5-9)$ except for $F$ that was made once with $\mathrm{n}=3 .{ }^{*} P<0.05 ;{ }^{* *} P<0.01 ;{ }^{* * *} P<0.001$. MAL-II $=$ Maackia amurensis lectin II; $\mathrm{CpNEU}=$ neuraminidase Clostridium perfringens. 

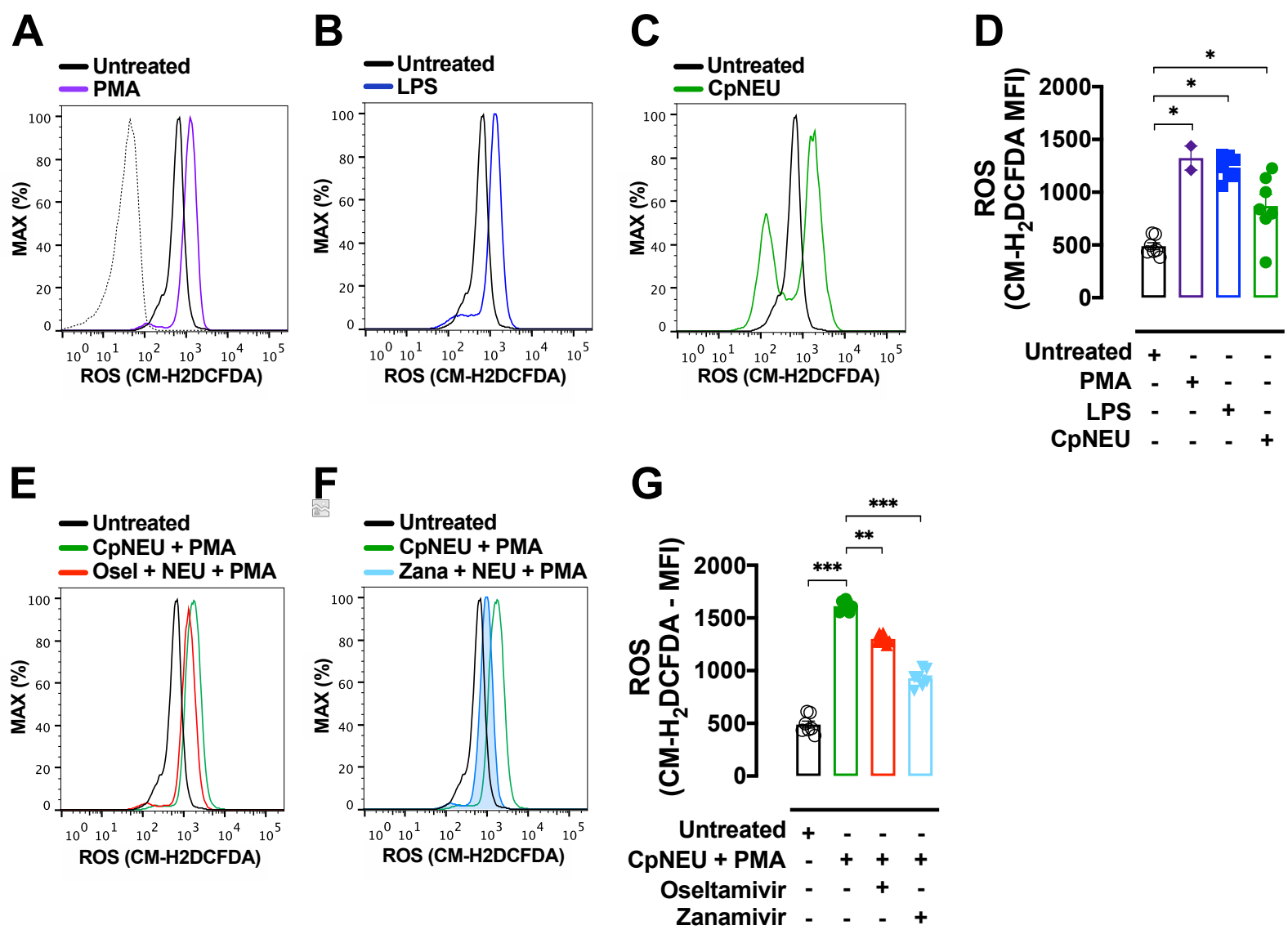

\section{Supplementary Fig. 5. ROS production in neutrophils stimulated with LPS, CpNEU,} or PMA. Whole blood from healthy donors containing $1 \times 10^{6}$ leukocytes were exposed or not to LPS $(1 \mu \mathrm{g} / \mathrm{mL}, 90 \mathrm{~min})$ (B and D). Total leukocytes $\left(1 \times 10^{6}\right)$ were incubated or not with CpNEU (10 mU, 60 min) (C-D), CpNEU plus Oseltamivir $(100 \mu \mathrm{M})$ or CpNEU plus Zanamivir $(30 \mu \mathrm{M})(\mathrm{E}-\mathrm{G})$. Leukocytes were incubated with $5 \mu \mathrm{M} \mathrm{CM}-\mathrm{H}$ 2DCFDA fluorescent probe for 15 min and PMA $(10 \mu \mathrm{M})$ was used to stimulate ROS production for 10 min (A and E-G). The MFI was analyzed on $\mathrm{CD} 6 \mathrm{~b}^{+}$cells. Symbols represent individual donors and data are shown as mean \pm SEM from pooled data of two independent experiments $(\mathrm{n}=2-6) .{ }^{*} P<0.05 ;{ }^{* *} P<0.01 ;{ }^{* *} P<0.001 . \mathrm{C}=$ control; $\mathrm{CM}-$ H2DCFDA = 5-(and-6)-chloromethyl-2',7'-dichlorodihydrofluorescein diacetate, acetyl 
bioRxiv preprint doi: https://doi.org/10.1101/2020.11.12.379115; this version posted May 20, 2021. The copyright holder for this preprint (which

was not certified by peer review) is the author/funder, who has granted bioRxiv a license to display the preprint in perpetuity. It is made available under aCC-BY-NC-ND 4.0 International license.

ester; LPS = lipopolysaccharide; $\mathrm{CpNEU} \mathrm{=} \mathrm{neuraminidase} \mathrm{Clostridium} \mathrm{perfringens;} \mathrm{PMA}$ $=$ phorbol 12-myristate 13-acetate. 


\section{O Naive $\quad$ E. coli $\triangle$ Osel + E. coli}
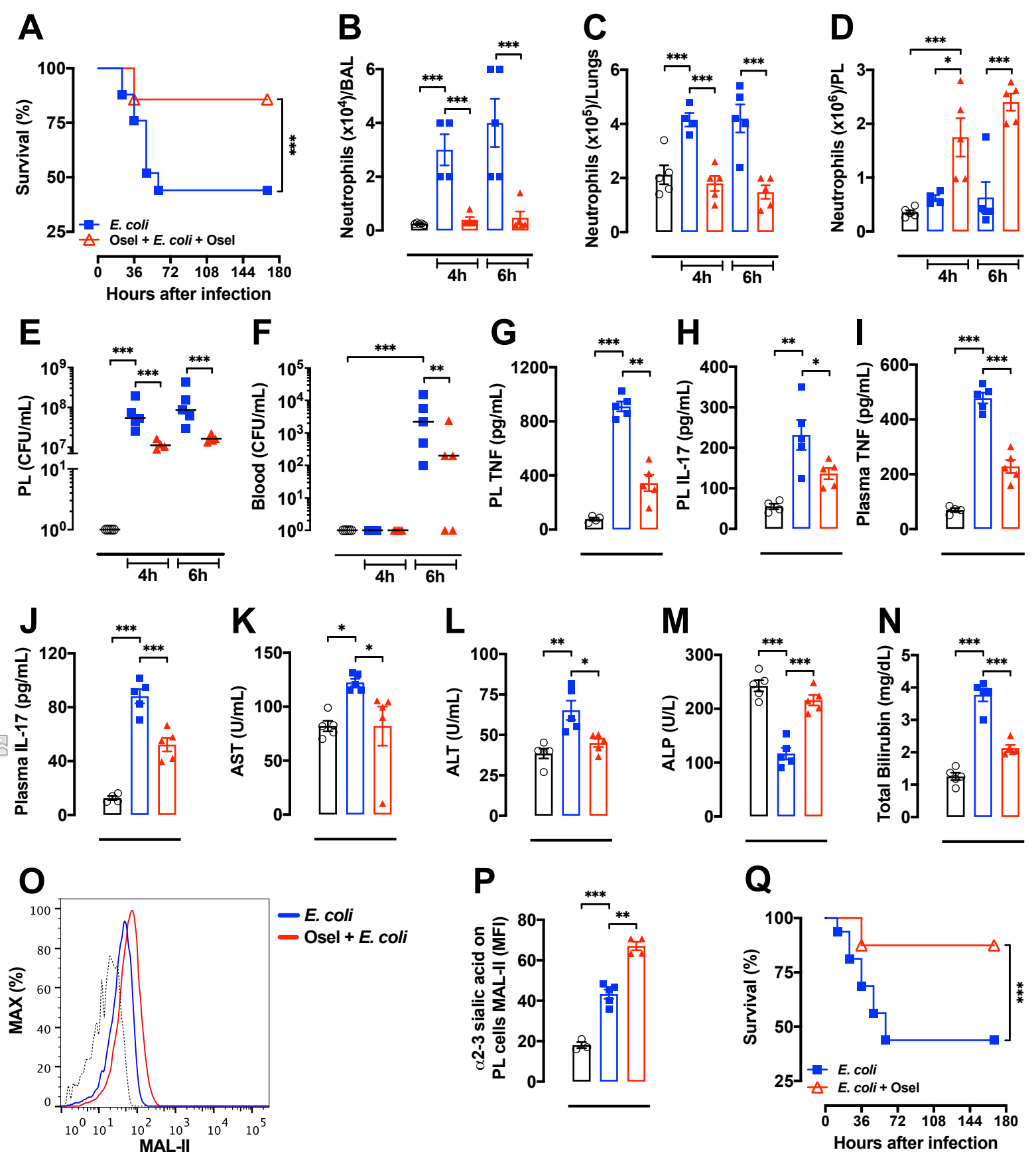

Supplementary Fig. 6. Oseltamivir improved the outcome of E. coli-induced sepsis.

Sepsis was induced by intraperitoneal (IP) administration of $1 \times 10^{7} \mathrm{CFU} / \mathrm{mice}$ E. coli (ATCC 25922). Mice were randomly pretreated per oral (PO) via (2 hr before infection) and posttreated (6 hr after infection, 12/12 hr, PO, for 4 days) with Oseltamivir phosphate 
(Osel, $10 \mathrm{mg} / \mathrm{Kg}$ ) or saline and their survival rates were monitored over $168 \mathrm{hr}(\mathbf{A}, \mathrm{n}=16)$. In another set of experiments $(n=3-5)$ mice were randomly pretreated (2 $\mathrm{hr}$ before infection) with Oseltamivir phosphate $(10 \mathrm{mg} / \mathrm{Kg}, \mathrm{PO})$ and the number of neutrophils in bronchoalveolar lavage (BAL, B) and in lung tissue (C) was counted. In peritoneal lavage $(P L)$ infiltrating neutrophils counts $(\mathbf{D})$, TNF $(\mathbf{G}), \mathrm{IL}-17(\mathbf{H})$ and the number of colonyforming units (CFU) in PL (E) or blood (F) were determined 4 or $6 \mathrm{hr}$ after infection. Plasma levels of TNF (I), IL-17 (J), AST (K), ALT (L), ALP (M) and total bilirubin (N) were evaluated. The amount of surface $\alpha 2-3$ sialic acids were also assessed in PL SSC ${ }^{\text {high }} / \mathrm{Gr}-$ $1^{\text {high }}$ cells as shown by the representative histograms $(\mathbf{O})$ or $\mathrm{MFI}(\mathbf{P})$; dotted line = unstained cells. Mice were also randomly posttreated (starting $6 \mathrm{hr}$ after infection, 12/12 hr, PO, for 4 days) with saline or Oseltamivir phosphate $(10 \mathrm{mg} / \mathrm{Kg})$ and their survival rates were monitored over $168 \mathrm{hr}(\mathbf{Q})$. The results are expressed as percent of survival ( $\mathrm{n}=16$ ), mean or median (only for FACS data) \pm SEM. ${ }^{*} P<0.05 ;{ }^{* *} P<0.01 ;{ }^{* *} P<0.001$. These experiments were repeated 3 times for survival analysis and twice for other parameters. Osel = Oseltamivir; AST = alanine aminotransferase; $A L T=$ aspartate aminotransferase; ALP = alkaline phosphatase; MAL-II = Maackia amurensis lectin II. 

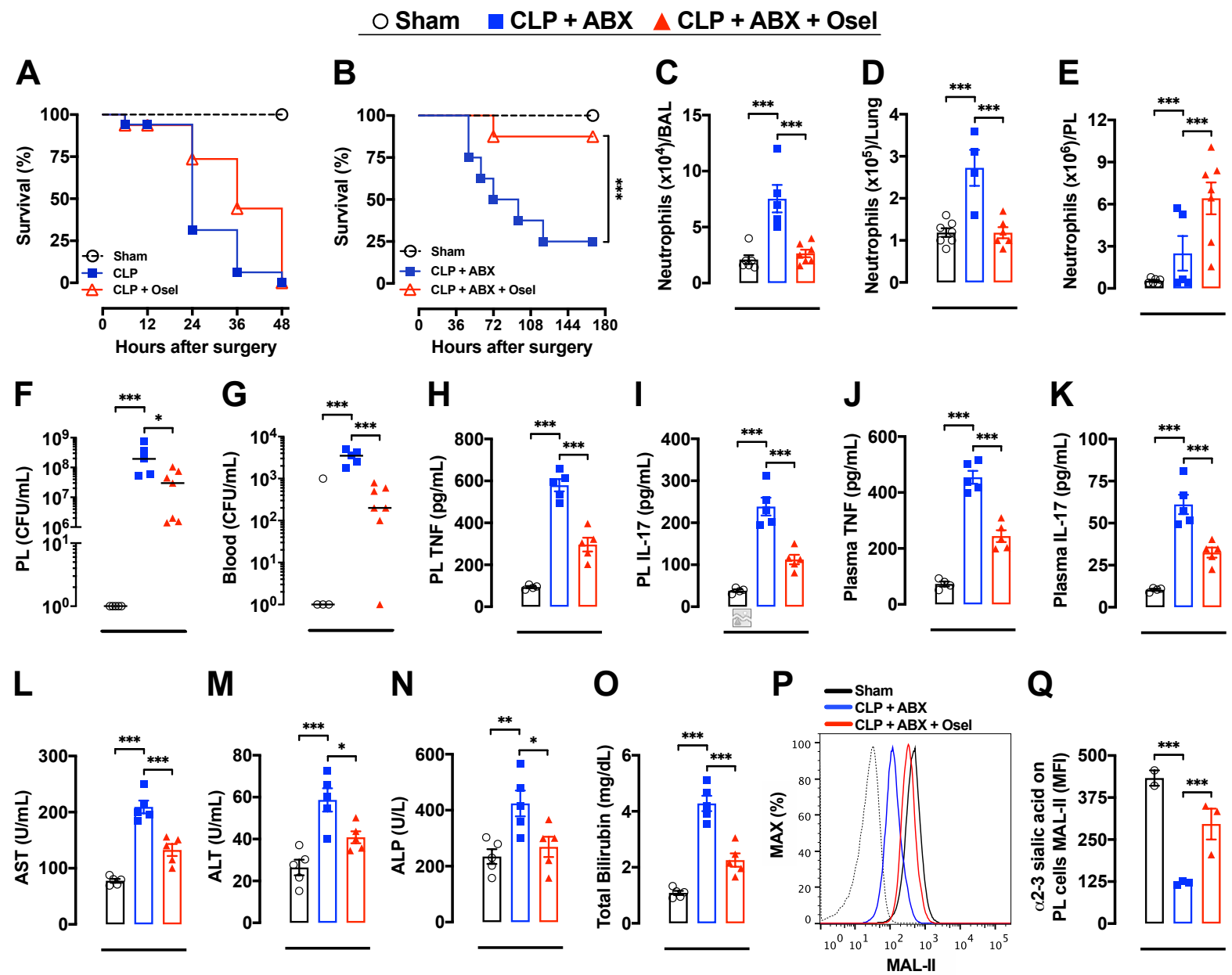

Supplementary Fig. 7. Oseltamivir enhanced host survival in CLP-induced sepsis.

Severe sepsis was induced by the cecal ligation and puncture (CLP) model. Mice were randomly treated (starting $6 \mathrm{hr}$ after infection, $12 / 12 \mathrm{~h}, \mathrm{PO}$, for $36 \mathrm{hr}, \mathrm{n}=16$ ) with saline or Oseltamivir phosphate $(10 \mathrm{mg} / \mathrm{kg})$ and their survival rates were monitored over $48 \mathrm{hr}(\mathbf{A})$. In another set of experiments, CLP mice were randomly IP treated (started $6 \mathrm{hr}$ after infection, $12 / 12 \mathrm{hr}$ ) during 4 days with $100 \mu \mathrm{L}$ metronidazole $(15 \mathrm{mg} / \mathrm{kg}) /$ ceftriaxone (40 $\mathrm{mg} / \mathrm{kg})(A B X)$ plus saline or Oseltamivir phosphate $(10 \mathrm{mg} / \mathrm{kg})$ by PO and their survival rates $(n=12)$ were monitored over $168 \mathrm{hr}(\mathrm{B})$. Also, mice were subjected to CLP and treated with $A B X+$ saline or $A B X+$ Olsetamivir as described in $B$ and euthanized $48 \mathrm{hr}$ after surgery to evaluate the number of neutrophils in BAL (C), lung tissue (D), and 
peritoneal lavage $(\mathrm{PL})(\mathbf{E})$; TNF (H), IL-17 (I), and CFU (F) were also determined in PL. Blood CFU (G) and plasmatic levels of TNF (J), IL-17 (K), AST (L), ALT (M), ALP (N) and total bilirubin (0) were also evaluated $48 \mathrm{hr}$ after surgery. The amount of surface $\alpha 2-3$ sialic acids were assessed by MAL-II staining in SSC ${ }^{\text {high }} / \mathrm{Gr}-1^{\text {high }}$ cells in PL and analyzed by FACS, as shown by the representative histograms $(\mathbf{P})$ and $\mathrm{MFI}(\mathbf{Q})$; dotted line = unstained cells. The results are expressed as percent of survival $(n=16)$, mean or median (only for FACS data) \pm SEM. ${ }^{*} P<0.05 ;{ }^{* *} P<0.001$. These experiments were repeated 3 times for survival analysis and twice for other parameters $(n=3-7)$. ABX = antibiotics (metronidazole/ceftriaxone); Sham = sham- operated. Osel = Oseltamivir; AST = alanine aminotransferase; $\mathrm{ALT}$ = aspartate aminotransferase; $\mathrm{ALP}=$ alkaline phosphatase; CFU = colony-forming units 
A

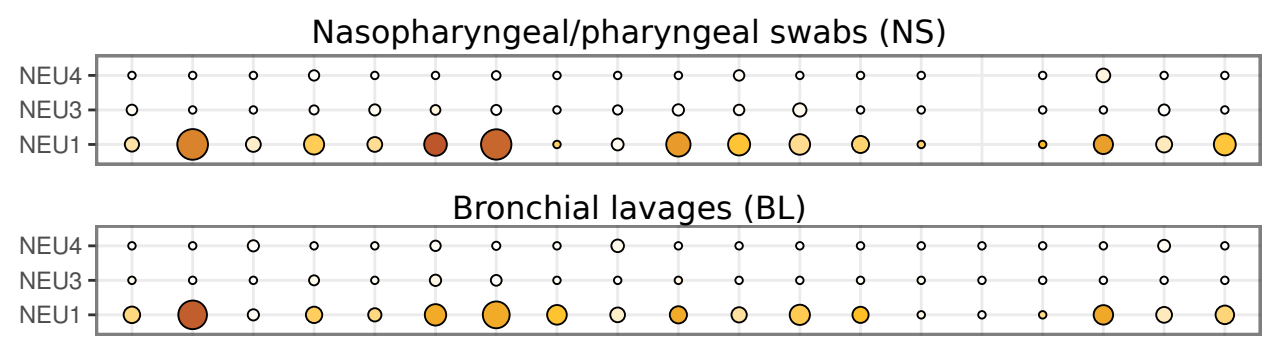

Percentage

Bronchial protected specimen brushes (PSB)

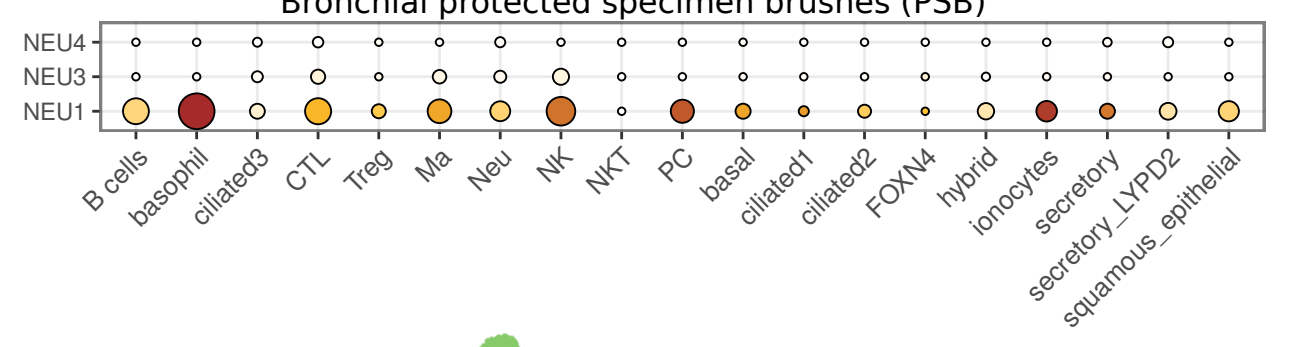

$\circ 0$

(10

○ 20

Average expression

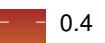

0.3

0.2

0.1

0.0

B
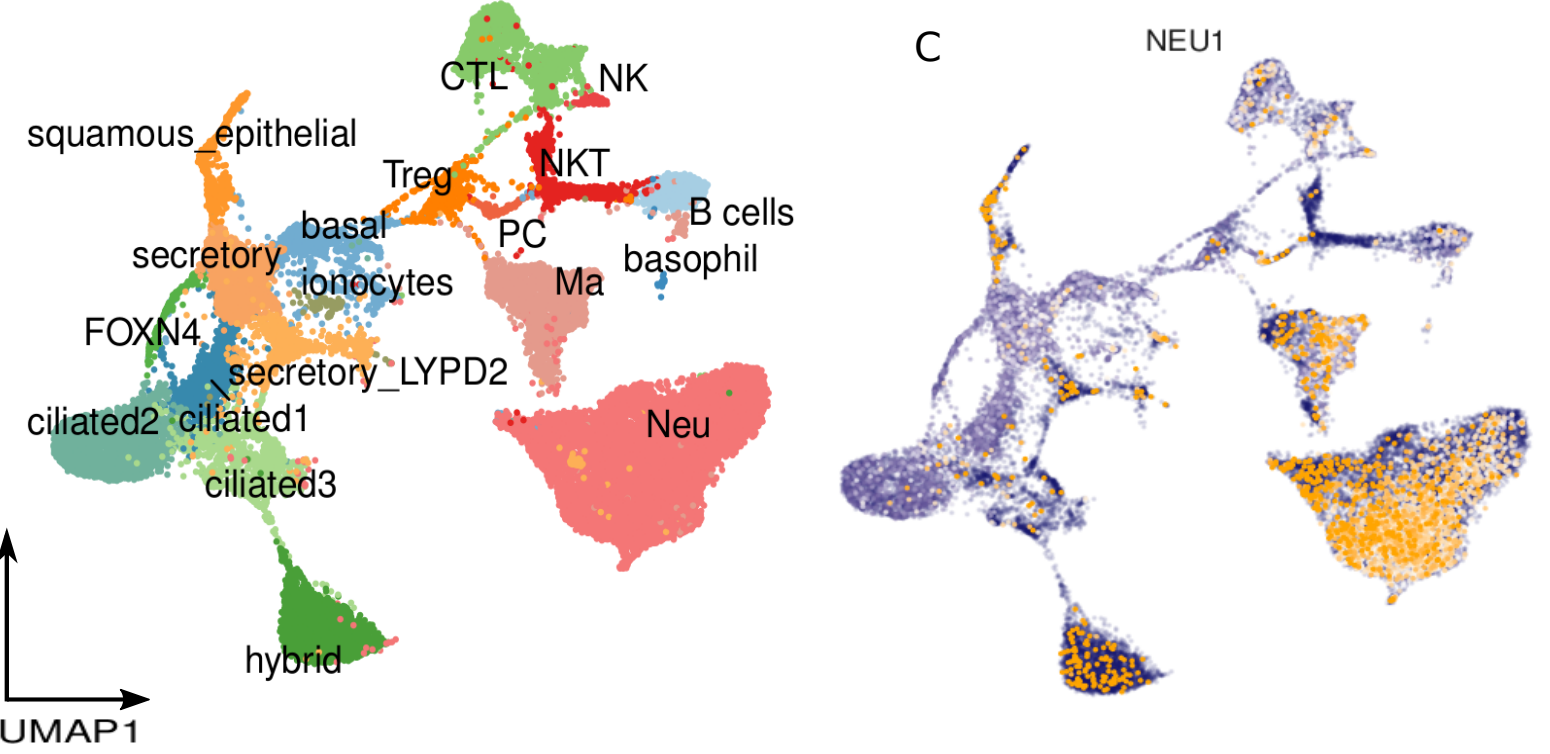

Supplementary Fig. 8. Expression of NEU1 in cell types from COVID-19 critical patients. (A) Gene expression of NEU1, NEU3 and NEU4 across cell types in two critical COVID-19 patients (BIH-CoV-01 and BIH-CoV-04). Size of the circle is proportional to the percentage of cells expressing the reported genes at a normalized expression level higher than one. (B) UMAP analysis colored-coded by cell types in NS, BL, and PSB samples from two critical COVID-19 patients. (C) Normalized expression of NEU1 overlaid on the UMAP space. 
A

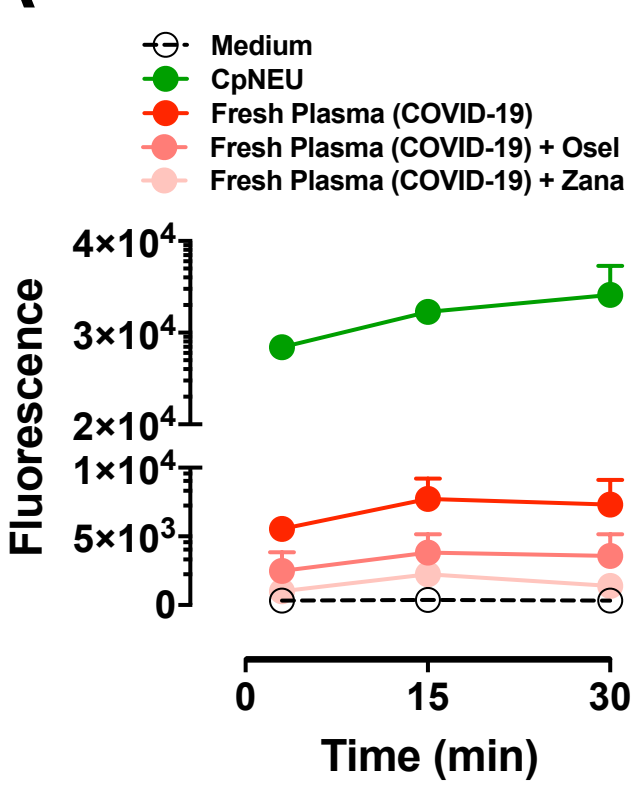

B

Fresh Plasma (COVID-19)

$\checkmark$ - Heat-inactivated Plasma (COVID-19)

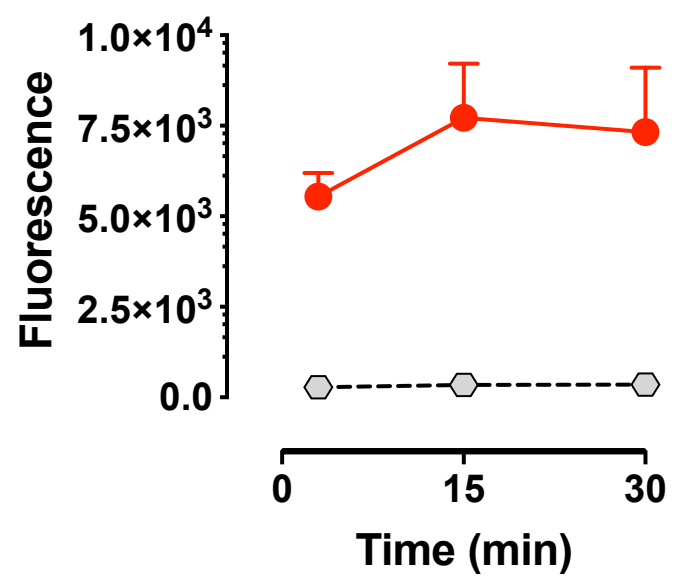

Supplementary Fig. 9. NEU activity is increased in plasma from severe COVID-19 patients. NEU activity was evaluated in fresh plasma from severe COVID-19 patients in the presence or absence of Oseltamivir $(100 \mu \mathrm{M})$ or Zanamivir $(30 \mu \mathrm{M})(\mathbf{A})$ and in heatinactivated plasma from COVID-19 patients (B). Neuraminidase isolated from Clostridium perfringens (CpNEU) was used to validate the NEU activity assay. MAL-II = Maackia amurensis lectin II; CpNEU = neuraminidase Clostridium perfringens . 


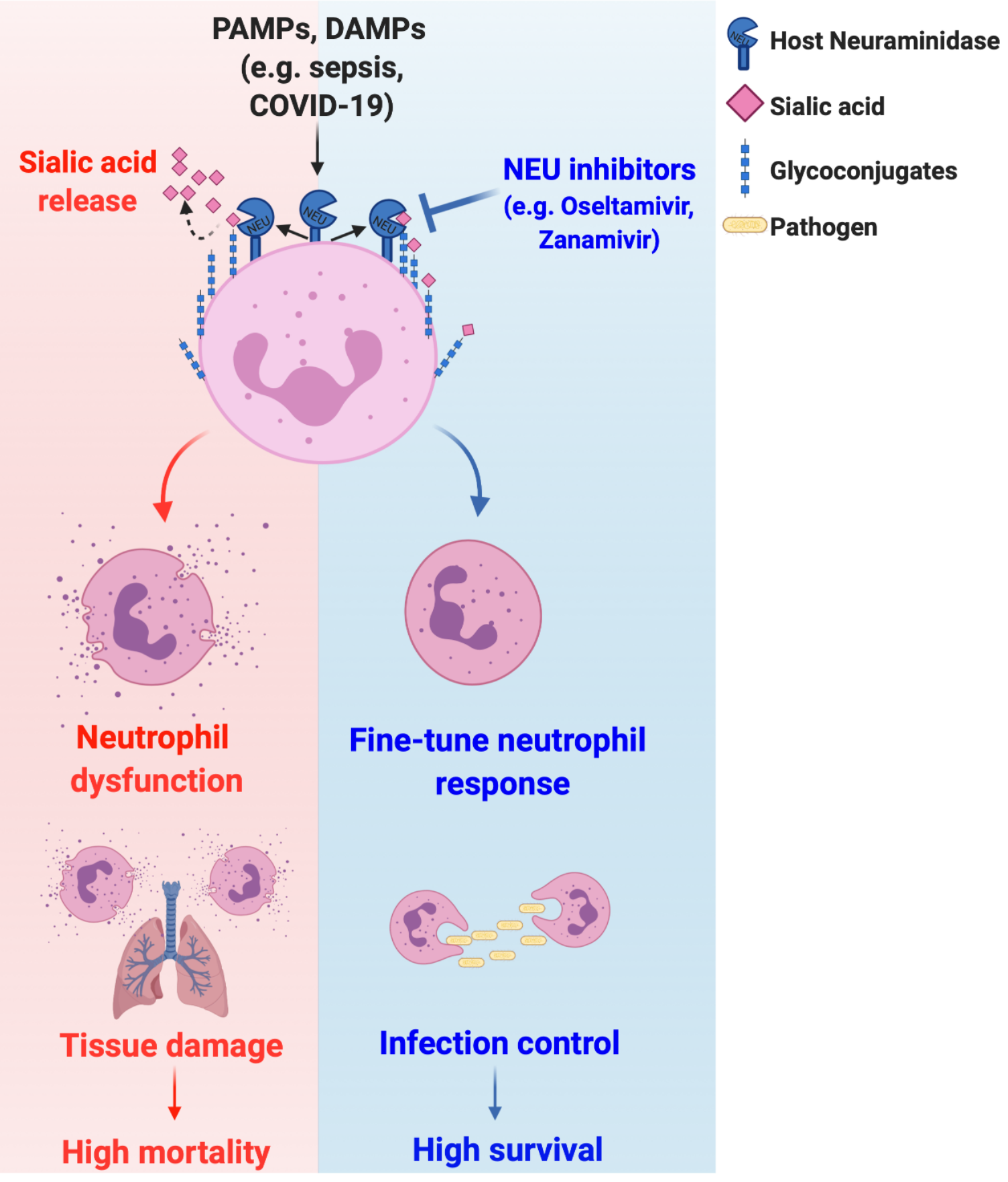

Supplementary Fig. 10. Working model. PAMPs and DAMPs in severe diseases such as sepsis and COVID-19 lead to neuraminidase activation with shedding of surface sialic acid and neutrophil overactivation, resulting in tissue damage and high mortality rates. On the other hand, neuraminidase inhibitors (e.g., Oseltamivir, Zanamivir) prevent the 
bioRxiv preprint doi: https://doi.org/10.1101/2020.11.12.379115; this version posted May 20, 2021. The copyright holder for this preprint (which

was not certified by peer review) is the author/funder, who has granted bioRxiv a license to display the preprint in perpetuity. It is made available under aCC-BY-NC-ND 4.0 International license.

sialic acid release to regulate neutrophil response, resulting in infection control and high survival rates. 